\title{
Pseudomonas syringae, bactérie épiphyte, glaçogène et pathogène
}

\author{
JL Gaignard, J Luisetti * \\ INRA, station de pathologie végétale et phytobactériologie, centre d'Angers, 42, rue G-Morel, \\ BP 57, F49071 Beaucouzé Cedex, France
}

(Reçu le 2 octobre 1992; accepté le 20 février 1993)

Résumé - Pseudomonas syringae, l'une des 50 espèces bactériennes phytopathogènes, est caractérisée par une grande variabilité génétique, physiologique et biologique qui s'exprime au travers des 52 pathovars qui la composent. L'espèce Pseudomonas syringae, décrite sur près de 400 espèces végétales (le seul pathovar syringae a été signalé sur 177 hôtes), possède 3 propriétés importantes : un pouvoir pathogène, un pouvoir glaçogène et une aptitude à la vie épiphyte.

Dans une première partie, les principales caractéristiques de l'espèce, hormis les caractères génétiques non significativement développés ici, sont présentées. Dans la seconde partie, les 3 propriétés remarquables sont analysées en détail.

L'aptitude épiphyte de Pseudomonas syringae s'exprime par une capacité à coloniser la surface des organes aériens des plantes, à s'y multiplier de façon importante. Elle conduit à l'existence de niveaux de population élevés au printemps, et en automne aussi pour les plantes pérennes; ces populations épiphytes constituent un réservoir d'inoculum et sont essentielles pour l'initiation de l'infection. La distribution de ces populations épiphytes, en général abondantes, n'est pas homogène ni entre plantes, ni entre organes d'une même plante ; leur répartition à la surface de la feuille qui constitue leur support essentiel est aussi très hétérogène. La nature de l'interaction entre l'hôte et les bactéries épiphytes n'est pas connue ; l'existence d'un lien entre spécificité parasitaire et la spécificité épiphyte au sein de l'espèce syringae est suspectée.

Le pouvoir glaçogène de l'espèce syringae s'exprimant par une capacité à induire une rupture précoce de la surfusion de l'eau ne concerne qu'une fraction de pathovars, essentiellement le pathovar syringae. On a montré qu'il était impliqué dans la gélivité des plantes au printemps (vigne, arbres fruitiers, tomate, pomme de terre...) et qu'il est l'un des facteurs favorisant les premières phases de l'infection bactérienne.

Le pouvoir pathogène de Pseudomonas syringae montre une spécificité d'hôte liée au pathovar considéré, sauf pour le pathovar syringae dont la gamme d'hôtes est actuellement contestée par plusieurs auteurs. Le développement de l'infection est conditionné par l'existence de voies de pénétration naturelles (elles sont limitées) ou artificielles (blessures) offertes à l'inoculum ; les conditions climatiques pendant les phases initiales de l'infection et durant l'incubation apparaissent capables de moduler l'intensité de l'infection.

La connaissance de l'ensemble de ces données permet une esquisse générale de cycle biologique à partir duquel des stratégies de lutte peuvent être élaborées ; différents exemples sont alors présentés en appui.

Diverses perspectives de recherches sur cette espèce bactérienne sont discutées.

\section{Pseudomonas syringae / aptitude épiphyte / activité glaçogène / pouvoir pathogène / lutte}

Summary - Pseudomonas syringae, an epiphytic ice nucleation active and phytopathogenic bacterium. Pseudomonas syringae, one of the 50 phytopathogenic bacterial species, is the most frequently occurring bacterium under temperate climatic conditions. P syringae has been isolated from $\approx 400$ different plant hosts (177 hosts for $p \mathrm{v}$ syringae) and is characterized by high genetic, physiological and biological variability expressed through 52 pathovars. Three important properties are associated with this species: pathogenicity, ice nucleation activity and ability for epiphytic survival. The general characteristics of $\mathrm{P}$ syringae, apart from the genetic aspects, which have not been examined here, are presented in the first part of this review. In the second part, the 3 remarkable properties of the species have been analyzed. Epiphytic survival, expressed by a capacity to colonize aerial parts of plants or by a significant epiphytic multiplication characterizes most pathovars. High levels of epiphytic populations can be recovered in the spring and also in autumn for perennial plants. These epiphytic populations constitute an inoculum source and are essential to the development of infection.

\footnotetext{
* Correspondance et tirés à part
} 
The generally abundant distribution of epiphytic populations is not homogeneous, either between or within plants; their distribution on the surface of the leaf which constitutes their main support is also very heterogeneous. The nature of the interaction between epiphytic bacteria and their host is not yet known, but a relation between host specificity for pathogenicity and host specificity for epiphytic capability within $\mathrm{P}$ syringae has been hypothesized.

The ice nucleation activity of $\mathrm{P}$ syringae, expressed as the ability to induce an early nucleation of water, concerns only some pathovars, mainly the pathovar syringae.

It has been shown to be involved in the ice nucleation of plants and frost damage in spring (eg grapevine, tomato, potato) and to be one of the favorable factors in the first stages of some bacterial infections. The pathogenicity of Pseudomonas syringae is dependent on the pathovar except for pv syringae which exhibits a rather wide host range. Some authors have contested this host range for the latter pathovar.

The development of infection caused by Pseudomonas syringae is conditioned by the existence of natural (these are limited) or artificial (wounds) means of penetration into the plant tissues and by the inoculum level. Climatic conditions during the first stages of infection or during the incubation period appear to be involved in the modulation of disease intensity.

These biological data are useful in understanding the life cycle of $\mathrm{P}$ syringae and in elaborating an efficient strategy for disease control; different examples are then presented for illustration. Finally, further developments of research on this phytopathogenic bacterium have been discussed.

Pseudomonas syringae / epiphyte / ice nucleation / pathogenicity / control

\section{PLACE DE PSEUDOMONAS SYRINGAE AU SEIN DES BACTÉRIES PHYTOPATHOGĖNES}

\section{Importance des maladies bactériennes des plantes}

Les maladies bactériennes des plantes ont probablement toujours existé à l'état endémique. Dans la Grèce antique, Théophraste, contemporain d'Aristote, a décrit, entre autres maladies, les tubercules de l'olivier, que nous savons aujourd'hui être des tumeurs d'origine bactérienne (Pseudomonas syringae pv savastanol). Plusieurs espèces bactériennes, pathogènes de plantes, ont été signalées et décrites dès le début du XXe siècle, Pseudomonas syringae, Pseudomonas solanacearum, Erwinia amylovora, Agrobacterium rhizogenes et $A$ tumefaciens. L'intensification de la production et des échanges internationaux, la création de matériel végétal nouveau et sa propagation géographique ont contribué à accroître l'importance des maladies bactériennes des plantes.

On dénombre actuellement plus de 250 espèces ou pathovars bactériens dont le pouvoir pathogène a été vérifié sur les plantes. Ils appartiennent aux genres Agrobacterium, Clavibacter, Curtobacterium, Erwinia, Pseudomonas, Rhodococccus, Xanthomonas et Xylophilus (tableau I). Les répercussions économiques consécutives au développement de certaines bactérioses dans les cultures peuvent être catastrophiques: on peut citer, à titre d'exemples, le flétrissement bactérien des Solanacées et des Musacées dû à $P$ solanacearum qui, dans certaines régions tro- picales ou subtropicales, interdit la culture de la pomme de terre ; la bactériose du riz provoquée par Xanthomonas campestris pv oryzae; le feu bactérien de rosacées fruitières et ornementales (Erwinia amylovora) ; le dépérissement bactérien du pêcher ( $P$ syringae pv persicae). Certaines maladies doivent à leur gravité de figurer sur les listes de quarantaine établies par les pays importateurs (feu bactérien).

\section{Le genre Pseudomonas}

Le genre Pseudomonas constitue l'1 des 8 genres bactériens incluant des espèces phytopathogènes. Créé en 1894 par Migula, ce genre bactérien compte aujourd'hui de nombreuses espèces qui colonisent le sol, la rhizosphère, la phyllosphère, les tissus végétaux et animaux en décomposition, l'eau douce et l'eau de mer. Quelques espèces sont pathogènes des animaux ou de l'homme (Prévot, 1961), en particulier $P$ aeruginosa.

En 1902, Van Hall, relayant les observations de Sorauer (1891) en Allemagne et de Ritzema (1899) aux Pays-Bas (d'après Bryan, 1928) et les travaux non publiés de Bejerinck en Angleterre, caractérise comme un Pseudomonas la bactérie isolée par ce dernier à partir de lésions sur lilas; il l'a nommée $P$ syringae ( $P s$ pv syringae selon la nomenclature actuelle).

Aujourd'hui, les Pseudomonas phytopathogènes sont classés dans 2 groupes (Palleroni, 1984). Le premier rassemble les bactéries qui (i) n'accumulent pas le poly- $\beta$-hydroxybutyrate et 
Tableau I. Liste des bactéries citées, auteurs et année de description (d'après Bergey's Manual of systematic Bacteriology 1984. Bradbury 1986; Moore et Moore, 1989).

Agrobacterium

A rhizogenes (a)

A tumefaciens (a)

Clavibacter

Curtobacterium (a)

Erwinia

E amylovora (a)

E carotovora (a)

E herbicola ${ }^{(b)}$

\section{Escherichia coli (c)}

Pseudomonas

$P$ aeruginosa $(\mathrm{c}, \mathrm{f})$

$P$ cichorii $(\mathrm{a}, \mathrm{f})$

$P$ fluorescens $(\mathrm{b}, \mathrm{d}, \mathrm{f})$

$P$ marginalis $(\mathrm{a}, \mathrm{f})$

$P$ putida $(\mathrm{b}, \mathrm{f})$

$P$ syringae (a,f)

$P$ s pv coronofaciens $(\mathrm{a}, \mathrm{f})$

$P$ s pv glycinea $(\mathrm{a}, \mathrm{f})$

$P s$ pv lachrymans $(a, f)$

$P$ s pv morsprunorum $(\mathrm{a}, \mathrm{f})$

$P$ s pv papulans $(\mathrm{a}, \mathrm{f})$

$P$ s pv persicae $(\mathrm{a}, \mathrm{f})$

$P s$ pv phaseolicola $(a, f)$

$P s$ pv pisi $(\mathrm{a}, \mathrm{f})$

$P$ s pv savastanoi $(\mathrm{a}, \mathrm{f})$

$P s$ pv syringae $(\mathrm{a}, \mathrm{f})$

$P s$ pv tabaci $(\mathrm{a}, \mathrm{f})$

$P s$ pv tomato $(a, f)$

$P$ caryophylli $(\mathrm{a}, \mathrm{f})$

$P$ cepacia $(\mathrm{a}, \mathrm{g})$

$P$ gladioli $(\mathrm{a}, \mathrm{f})$

$P$ solanacearum $(\mathrm{a}, \mathrm{g})$

$P$ viridiflava $(\mathrm{a}, \mathrm{f})$

\section{Rhodococcus}

Xanthomonas

$X$ c pv oryzae (a)

$X$ c pv translucens (a)

Xylophilus ampelinus $(\mathrm{a}, \mathrm{e})$
Conn, 1942

(Riker et al) Conn, 1942 / nombreuses plantes

(Smith et Townsend) Conn 1942 / nombreuses plantes

Davis et al, 1984

Yamada et Komagata, 1972

Winslow et al, 1920

(Burril) Winslow et al, 1920 / Pomoïdées fruitières et ornementales (Jones) Bergey et al, 1923 / nombreuses plantes

(Löhnis) Dye, 1964 / nombreuses plantes

(Migula) Castellani et Chalmers, 1919

Migula, 1894

(Schroeter) Migula, 1900

(Swingle) Stapp, $1928 /$ nombreuses plantes

(Trevisan) Migula, $1895 /$ nombreuses plantes

(Brown) Stevens, $1925 /$ nombreuses plantes

(Trevisan) Migula, 1895

Van Hall, 1902

(Elliott) Young et al, 1978 / graminées

(Coerper) Young et al, 1978 / soja

(Smith \& Bryan) Young et al, 1978 / cucurbitacées

(Wormald) Young et al, 1978 / Prunus spp

(Rose) Dhanvantari, 1977 / pommier et poirier

(Prunier, Luisetti et Gardan) Young et al, 1978 / pêcher

(Burkholder) Young et al, 1978/ haricot

(Sackett) Young et al, 1978 / pois

(Smith) Young et al, 1978 / oléacées

(Van Hall) Young et al, 1978 / lilas et nombreuses plantes

(Wolf et Foster) Young et al, 1978/ tabac

(Okabe) Young et al, 1978/ tomate

(Burkholder) Starr et Burkholder, 1942 / œillet

Burkholder, 1950 / oignon

Severini, 1913 / plusieurs plantes à bulbes

(Smith) Smith, 1914 / solanacées, musacées, légumineuses

(Burkholder) Dowson, 1939 / nombreuses plantes

Zopf, 1891

Dowson, 1939

(Ishiyama) Young et al, 1978 / riz

(Jones, Johnson et Reddy, Young et al, 1978 / graminées

(Panagopoulos, 1969) Willems et al, 1987 / vigne

(a) Bactéries phytopathogènes; (b) bactéries saprophytes; (c) bactéries pathogènes des espèces animales; (d) bactérie signalée une seule fois phytopathogène; (e) précédemment nommée Xanthomonas ampelina; ${ }^{(f)}$ groupe 1 selon Palleroni 1984; (g) groupe 2 selon Palleroni, 1984. 
(ii) produisent un pigment fluorescent, dans lequel on trouve les espèces phytopathogènes $P$ syringae, $P$ viridiflava, $P$ cichorii. Les espèces de référence de ce groupe sont $P$ aeruginosa et une espèce saprophyte, fréquente sur les plantes et dans leur environnement, $P$ fluorescens.

Le second, rassemble des bactéries phytopathogènes (i) accumulant le poly- $\beta$ hydroxybutyrate et (ii) ne produisant pas de pigment fluorescent : il s'agit de $P$ solanacearum, $P$ caryophylli, $P$ cepacia et $P$ gladioli qui sont des espèces phytopathogènes.

En dehors de $P$ solanacearum, essentiellement présent dans les zones tropicales et subtropicales, les espèces phytopathogènes appartenant au genre Pseudomonas sévissent surtout sur des plantes des zones à climat tempéré. Aujourd'hui, l'espèce $P$ syringae a été signalée dans 57 pays, répartis sur l'ensemble du globe (Bradbury, 1986). Les espèces du genre Pseudomonas associées aux plantes sont présentées tableau I. Un certain nombre de pathovars de l'espèce $P$ syringae, affectant les plantes ligneuses des pays tempérés, sont présentés tableau II.

\section{L'espèce $\mathrm{P}$ syringae et ses pathovars}

Cette espèce a été récemment subdivisée en pathovars (ou pathotypes) distingués pour leur pouvoir pathogène différentiel (Young et al, 1978; Dye et al, 1980).

Bradbury (1986) dénombre 52 pathovars à l'intérieur de l'espèce $P$ syringae, signalés pathogènes sur 400 espèces végétales. Dès 1962, Cameron note que l'espèce $P$ syringae a été isolée sur la plupart des arbres fruitiers. Certains pathovars sont spécifiques d'une seule espèce végétale, comme le pathovar persicae sur pêcher, alors que d'autres sont signalés sur un très grand nombre de plantes, comme le pathovar syringae isolé de 177 espèces végétales. Après inoculation artificielle d'une souche de $P s$ pv syringae isolée de lilas, sur 133 plantes ligneuses, Kagiwata et al (1990a) ont obtenu des dégâts sur 74 d'entre elles. La diversité intrapathovar est également remarquée chez le pathovar syringae (Luisetti et al, 1973a; Arsenijevic, 1986; Luisetti et Gaignard, 1987a; Hirano et Upper, 1990; Gardan et al, 1990; Young, 1991), caractérisé par son ubiquité. Chez des pathovars spécifiques d'une seule espèce végétale, la question

Tableau II. Pathovars de $P$ syringae affectant des plantes ligneuses des pays tempérés.

\begin{tabular}{|c|c|c|c|}
\hline Espèce, pathovar & Pays & Auteurs & Plantes \\
\hline \multirow[t]{9}{*}{ Pspv morsprunorum } & Afrique du Sud & $\begin{array}{l}\text { Hattingh et al, } 1989 \\
\text { Roos et Hattingh, } 1986 b\end{array}$ & Cerisier \\
\hline & Angleterre & Crosse, 1956; 1966 & $"$ \\
\hline & & Crosse et Garrett, 1970 & Cerisier, prunier \\
\hline & États-Unis & Latorre et Jones, 1979a & Cerisier \\
\hline & France & Prunier, 1986 & \\
\hline & & Prunier et Cotta, 1987 & Abricotier \\
\hline & Italie & Ercolani, 1969a; 1969b & Cerisier \\
\hline & Japon & Takanashi, 1988 & $"$ \\
\hline & Pologne & Sobiczewski, 1978 & $"$ \\
\hline \multirow[t]{6}{*}{$P s \mathrm{pv}$ persicae } & France & Gardan et al, 1971 & Pêcher \\
\hline & & Luisetti et al, 1984 & \\
\hline & & Luisetti et al, 1992 & $"$ \\
\hline & & Prunier et al, 1970a; 1973 & " \\
\hline & & Vigouroux, $1968 ; 1970$ & $"$ \\
\hline & Nouvelle-Zélande & Young, 1988 & Pêcher et prunier du Japon \\
\hline \multirow[t]{5}{*}{$P$ spv syringae } & Allemagne & Sorauer, 1891 & Lilas \\
\hline & Afrique du Sud & Doidge, 1917 & Poirier \\
\hline & & Hattingh et al, 1989 & Poirier, pommier \\
\hline & & Mansvelt et Hattingh, 1985 & Poirier \\
\hline & & Roos et Hattingh, 1986b & Cerisier, poirier \\
\hline
\end{tabular}


Tableau II. Suite

\begin{tabular}{|c|c|c|c|}
\hline Espèce, pathovar & Pays & Auteurs & Plantes \\
\hline & \multirow[t]{5}{*}{ Angleterre } & Barker et Grove, 1914 & Poirier \\
\hline & & Crosse, 1955; 1966 & Cerisier \\
\hline & & Garrett et al, 1966 & Cerisier, prunier, poirier \\
\hline & & Panagopoulos et Crosse, 1964 & Poirier \\
\hline & & Wormald, 1931 & Prunier \\
\hline & Argentine & Klingner et al, 1976 & Vigne \\
\hline & Canada & Mc Keene, 1925 & Poirier \\
\hline & Chili & Cancino et al, 1974 & $"$ \\
\hline & Espagne & Montesinos et Vilardell, 1991 & $"$ \\
\hline & \multirow[t]{13}{*}{ États-Unis } & Bryan, 1928 & Lilas \\
\hline & & Cameron, 1962; 1970 & Cerisier \\
\hline & & Canfield et al, 1986 & $\begin{array}{l}\text { Lilas, magnolia, tilleul, } \\
\text { peuplier, poirier, pommier }\end{array}$ \\
\hline & & Davis et English, 1969 & Pêcher \\
\hline & & Endert et Ritchie, 1984 & $"$ \\
\hline & & Griffin, 1911 & Cerisier \\
\hline & & Gross et al, 1984a & Poirier, pommier, Prunus spp \\
\hline & & Latorre et al, 1985 & Cerisier \\
\hline & & Opgenorth et Lai, 1983 & Kiwi \\
\hline & & Otta et English, 1970 & Prunier \\
\hline & & Parker et Burkholder, 1950 & Poirier, pommier \\
\hline & & Wilson, 1934 & Poirier \\
\hline & & Whitesides et Spotts, 1991 & $"$ \\
\hline & \multirow[t]{7}{*}{ France } & Cottin, 1989 & Laurier palme \\
\hline & & Gardan, 1980 & Forsythia, fusain du Japon \\
\hline & & Gardan et al, 1973 & Abricotier \\
\hline & & Gardan et al, 1989 & Laurier palme \\
\hline & & Luisetti et Gaignard, 1989a & Forsythia \\
\hline & & Luisetti et Gaignard, 1987b & Kiwi \\
\hline & & Luisetti et Gaignard, 1991 & Poirier \\
\hline \multirow[t]{14}{*}{ Pspv syringae } & & Prunier et Cotta, 1987 & Abricotier \\
\hline & & Rudé, 1967 & Lilas, noyer, poirier, pommier, Prunus spp \\
\hline & & Ridé et Sutic, 1957 & Poirier \\
\hline & Hongrie & Klement et al, 1972 & Abricotier \\
\hline & & Klement et al, 1974 & $"$ \\
\hline & Italie & Cucusi et al, 1986 & Vigne \\
\hline & & Ercolani, 1967 & Cerisier, poirier \\
\hline & Iran & Banapor et al, 1990 & Cerisier \\
\hline & Japon & Kagiwata et al, $1990 \mathrm{~b}$ & Lilas \\
\hline & Nouvelle-Zélande & $\begin{array}{l}\text { Dye, } 1956 \\
\text { Young, } 1978\end{array}$ & $\begin{array}{l}\text { Poirier } \\
\text { Prunus spp }\end{array}$ \\
\hline & Pays-Bas & Ritzéma, 1899 & Lilas \\
\hline & & Van Hall, 1902 & $"$ \\
\hline & Ukraine & Gvozdyak et Rassul, 1987 & Pommier \\
\hline & Yougoslavie & Arsenijevic, 1973 & Abricotier \\
\hline \multirow[t]{2}{*}{ P s pv papulans } & États-Unis & Burr et Katz, 1984 & Pommier \\
\hline & Italie & Bazzi et Calzolari, 1983 & $"$ \\
\hline
\end{tabular}


est également posée : Denny (1988) souligne la difficulté de sélectionner une souche représentative de $P s$ pv tomato pour mener des études approfondies sur ce pathovar.

Dans une synthèse récente, Hirano et Upper (1990) décrivent le rôle de l'espèce $P$ syringae dans la biologie de la phyllosphère: pathogène, épiphyte et glaçogène. En intégrant l'ensemble des connaissances portant sur ces 3 rôles, nous pouvons essayer d'approcher et de mieux comprendre l'écologie et la biologie des différentes bactéries qui composent l'espèce $P$ syringae. L'adaptation à de nombreuses espèces végétales, dans des environnements différents, a favorisé l'émergence de sous-populations (écotypes, pathotypes) résultant d'une sélection permanente, en réponse à la pression du milieu. La variabilité génétique de cette espèce bactérienne s'exprime à différents niveaux : physiologique, écologique et épidémiologique. Un pathovar peut être isolé de plusieurs espèces végétales, ce qui peut expliquer des variations intrapathovar. Gross et al (1984a) estiment que $P s$ pv syringae est un assemblage de groupes de souches caractérisés chacun par un spectre d'hôtes bien défini, hypothèse reprise par Hirano et Upper (1990) qui pensent qu'il y a une préférence d'hôte plutôt qu'une spécificité d'hôte.

\section{Les symptômes induits par $\mathrm{P}$ syringae}

Les symptômes provoqués par les Pseudomonas, comme pour la plupart des bactéries phytopathogènes, ne sont relativement caractéristiques qu'au début de leur apparition : les tissus infectés et gorgés d'eau (water soaking) prennent un aspect huileux à la limite de la lésion ; ces tissus altérés brunissent rapidement et peuvent être confondus avec des dégâts ayant d'autres origines (champignons, troubles physiologiques...). En général, seuls l'isolement de la bactérie, sa mise en culture et son identification permettent un diagnostic précis.

$P$ syringae est essentiellement un agent de type nécrogène qui provoque une destruction plus ou moins localisée des tissus parenchymateux. Des dégâts bactériens (nécroses) peuvent être observés sur fleurs (Mansvelt et Hattingh, 1987b; 1989), sur fruits (Luisetti, 1978), sur feuilles (nécrose parfois entourée d'un halo de chlorose évoluant ou non en criblure) (Vigouroux, 1970; Leben, 1981; Luisetti et al, 1984; Luisetti et al, 1992), sur jeunes pousses et charpentières (nécrose corticale ou chancre papyracé) (Luisetti, 1978; Malvick et Moore, 1988; Hattingh et al, 1989). L'organe peut ensuite pourrir, dans le cas où $P$ viridiflava est associé à $P s$ pv syringae, comme chez le kiwi (Luisetti et Gaignard, 1987b). La déformation du fruit est fréquente dans le cas de $P s$ pv syringae sur poirier (Luisetti, 1978), et de $P$ s pv persicae sur pêcher (Vigouroux, 1970); Luisetti et al, 1984). En général, les organes touchés tombent plus ou moins rapidement. Certains fruits arriveront à maturité, mais ils ne seront pas commercialisables.

Certains pathovars peuvent provoquer dans de rares cas des symptômes différents, par exemple l'infection de l'olivier par $P s$ pv savastanoi qui entraîne une prolifération tissulaire qui conduit à la formation de tumeurs sur les branches ou mêmes les feuilles des arbres atteints (laurier rose).

On a aussi décrit des pourritures associées à la présence de certains pathovars ( $p v$ lachrymans), mais cette manifestation reste exceptionnelle.

L'espèce $P$ syringae n'entraîne pas toujours la mort de la plante affectée mais peut réduire la croissance et la qualité des produits récoltés (Wimalajeewa et al, 1983), la longévité des arbres fruitiers (Endert et Ritchie, 1984), le niveau de production et la valeur commerciale des plantes ornementales (Gardan et al, 1989).

Comme toutes les bactéries phytopathogènes, $P$ syringae provoque une réaction d'hypersensibilité sur plante hétérologue dans la mesure où la concentration bactérienne infiltrée est supérieure à $10^{7}$ bactéries par $\mathrm{ml}$ (Klement, 1963). Le test est généralement fait sur feuilles de tabac dont les larges zones internervaires facilitent l'infection sous-épidermique de la suspension bactérienne à étudier. Après un début de multiplication, le germe (hétérologue) injecté ne peut envahir les tissus adjacents. La zone infiltrée est détruite (collapsus) et se dessèche en 24-48 $h$ (Klement et al, 1964; Hevesi et al, 1978).

Sur certaines plantes, le pouvoir glaçogène de $P s$ pv syringae peut être à l'origine du dessèchement d'organes lors des périodes de refroidissement (Luisetti et Gaignard, 1985; 1986; Prunier et Bordjiba, 1991). 


\section{CARACTÉRISTIQUES DE L'ESPÈCE P SYRINGAE}

\section{Taxonomie}

Les Pseudomonas appartiennent au groupe des Eubactéries non photosynthétiques, chimiotrophes, à l'ordre des Eubacteriales Buchanan (1917), à la famille des Pseudomonadaceae Winslow et al (1917), à la tribu des Pseudomonadeae Kluyver et Van Niel (1936).

L'espèce $P$ syringae appartient au genre $P$ seudomonas Migula (1984) et au groupe 1 selon I'ARNr (Palleroni et al, 1973) regroupant des $P$ seudomonas fluorescents dont $P$ viridiflava, $P$ fluorescens, $P$ putida et $P$ aeruginosa.

En 1966, Lelliott et al ont défini un schéma de détermination des espèces de Pseudomonas fluorescents isolés de plantes (tableau III) ; basé sur quelques caractères biochimiques sélectionnés et sur le test d'hypersensibilité sur tabac (Klement, 1963), il permet de séparer les espèces phytopathogènes des non pathogènes. Cette classification est reprise dans le Bergey's Manual of Determinative Bacteriology (1974).

Sands et al (1970), Hildebrand et Schroth (1972) ont complété le schéma par la prise en compte de caractères biochimiques complémentaires permettant de mieux séparer les organismes du groupe 1 décrit par Lelliott et al (1966) et qui correspond maintenant à l'espèce $P$ syringae.

Il est apparu, selon les règles du code international de nomenclature, que les faibles différences (quelques caractères biochimiques) observées entre espèces voisines ne justifiaient pas leur distinction. Ce constat a conduit à regrouper toutes les espèces de Pseudomonas phytopathogènes précédemment classées dans les groupes 1a et 1b (Lelliott et al, 1966) dans une seule espèce : $P$ syringae. Les phytobactériologistes ont cependant souhaité garder dans cette nouvelle nomenclature la prise en compte de la spécificité parasitaire de ces anciennes espèces en les dénommant "pathovar" (Young et al, 1978; Dye et al, 1980) ; ainsi, à l'intérieur de l'espèce $P$ syringae, chaque pathovar regroupe les souches bactériennes ayant la ou les mêmes plantes comme hôtes d'origine et qui, en outre, présentent un certain nombre de caractères identiques. Cette méthode de classification a été reprise en 1984 dans le Bergey's Manual of Systematic Bacteriology et en 1986 par Bradbury dans le Guide to Plant Pathogenic Bacteria. L'espèce $P$ syringae a été ainsi éclatée en 52 pathovars.

Cette classification taxonomique inclue la spécificité parasitaire pour la plupart des pathovars à l'intérieur de l'espèce $P$ syringae à l'exception de pv syringae lui même dont les différentes souches manifestent d'importantes variations (Latorre et Jones, 1979a; Gross et al, 1984a; Baca et Moore, 1987; Hirano et al, 1988; Malvick et Moore, 1988; Constantinidou et al, 1990), et dont parfois l'absence totale d'agressivité sur les plantes hôtes homologues de référence conduit à s'interroger sur la réalité de ce pathovar.

Une première école considère que toutes les souches possédant en commun (caractère de base) la faculté de déclencher une réaction d'hypersensibilité chez une plante hétérologue (le tabac - Klément, 1963) sont potentiellement pathogènes ; il faudrait alors chercher les causes des différences d'agressivité dans les relations complexes hôte - parasite - milieu.

Une seconde école, inspirée par les chercheurs américains, considère que le pathovar

Tableau III. Clé de détermination des Pseudomonas fluorescents adaptée de Lelliott et al (1966), permettant de déterminer l'espèce.

\begin{tabular}{|c|c|c|c|c|c|c|c|c|}
\hline Levane & Oxydase & Pectinolyse & $\begin{array}{c}\text { Arginine } \\
\text { dihydrolase }\end{array}$ & Tabac & Saccharose & Nitrates & Groupe & Espèce \\
\hline+ & - & - & - & + & + & - & $1 a$ & P syringae \\
\hline- & - & - & - & + & + & - & $1 b$ & P syringae \\
\hline- & - & + & - & + & - & - & 2 & $P$ viridiflava \\
\hline- & + & - & - & + & - & - & 3 & P cichorii \\
\hline$+1-$ & + & + & + & - & $+1-$ & $+1-$ & 4 & $P$ marginalis \\
\hline$+1-$ & + & - & + & - & $+1-$ & $+1-$ & 5 & P fluorescens \\
\hline
\end{tabular}


syringae, défini selon les tests proposés par Lelliott et al (1966), est hétérogène et comprend à la fois des souches pathogenes et des souches non pathogènes.

Le pathovar syringae tel qu'actuellement reconnu est certainement trop hétérogène pour être maintenu, comme le recommande Young (1991). Il pense que l'obtention de symptômes évolutifs sur lilas est, pour le moment, un des critères permettant de classer dans ce pathovar les nouvelles souches isolées. La méthodologie mise au point par Brisset et Paulin (1991) qui permet de caractériser les situations compatibles (maladie) et incompatibles (hypersensibilité) par la cinétique de fuite d'électrolytes pourrait également être associée à l'inoculation des souches sur une gamme d'hôtes judicieusement choisie. Young (1991) propose d'ailleurs aux phytobactériologistes de se prononcer sur la composition du pathovar syringae et de la considérer comme étant le rassemblement soit de toutes les souches pathogènes d'un hôte universel ou de quelques-uns, soit des souches pathogènes sur une gamme d'hôtes bien définie. Young et al (1991) proposent maintenant de prendre en compte le type de symptôme dans la notion de pathovar. Dans cette situation, encore confuse, certains auteurs préfèrent limiter à l'espèce la dénomination de nouvelles souches isolées.

L'hybridation ADN/ADN est la technique la moins constestée pour la définition de l'espèce. Palleroni et al (1972), Pecknold et Grogan (1973) ont pu, par hybridation ADN/ADN, regrouper des pathovars de l'espèce $P$ syringae dans 3 groupes d'homologie. Denny (1987), considère que seule la génétique permettra une définition claire et précise des pathovars de l'espèce $P$ syringae. De leur côté, Gardan et al (1990), estiment qu'une étude portant sur les caractères biochimiques, le pouvoir pathogène et l'hybridation ADN/ADN devrait permettre de clarifier la situation au sein de l'espèce.

\section{Caractères cytologiques et biochimiques}

La cellule de Pseudomonas est un bâtonnet droit ou bacille de taille moyenne de 0,7-3 $\mu \mathrm{m}$ de longueur sur $0,7-1 \mu \mathrm{m}$ d'épaisseur, isolé, en paires ou en chaînes, mobile par 1 à 3 flagelles polaires ; sa paroi ne retient pas la coloration de Gram (Gram négatif). Sur gélose nutritive, les colonies sont rondes, blanches et généralement lisses, convexes avec reflets bleus (Prévot, 1961).
$P$ syringae est une bactérie aérobie stricte, chimio-hétérotrophe, ne possédant pas de cytochrome $\mathrm{C}$ oxydase. La plupart des souches des différents pathovars cultivées sur milieu B de King (King et al, 1954) produisent un pigment jaune verdâtre et fluorescent sous UV : il s'agit d'un pigment hydrosoluble (pyoverdine).

La détermination des profils d'acides gras peut permettre une identification partielle des pathovars ; Sasser et Miller (1984) arrivent à identifier le genre, l'espèce et un pathovar ( $\mathrm{pv}$ tomato). Dans une étude similaire, Stead (1987), parvient à séparer certains pathovars à l'intérieur de l'espèce $P$ syringae, mais il ne peut distinguer les 2 espèces différentes: $P$ syringae et $P$ viridiflava.

En réalisant des électrophorèses des protéines pariétales des cellules bactériennes, Stead et Holland (1987), parviennent à identifier les pathovars présents sur pois ( $\mathrm{pv}$ syringae et pv pisi). Some et Samson (1991) distinguent $P$ cichorii, $P$ viridiflava, $P$ s pv pisi, $P$ s pv syringae et $P s$ pv tomato sur la base de leur profil estérasique. Tous ces auteurs pensent que les protéines natives et les iso-enzymes permettent de différencier les pathovars de $P$ syringae.

La capacité ou non de métaboliser par voie oxydative une gamme de substrats organiques est à la base de la méthodologie la plus utilisée pour identifier les différents pathovars de $P$ syringae (Lelliott et al, 1966; Sands et al, 1970; Hildebrand et Schroth, 1972; Mansvelt et Hattingh, 1985; Gardan et al, 1991). Les résultats mettent en évidence une variabilité importante liée aux souches et aux méthodes (Gross et al, 1984a; Luisetti et Gaignard, 1987a; Cottin, 1989). Roos et Hattingh (1987) constatent également l'extrême diversité du pathovar syringae, qu'ils expliquent par les nombreuses combinaisons possibles, climat, sol, espèce et méthodes culturales. En 1991, Young confirme que le pathovar syringae est celui qui, au sein de l'espèce, présente la plus grande variabilité au niveau des caractères biochimiques. En revanche, le pathovar morsprunorum signalé sur cerisier en Afrique du Sud est plus homogène (Roos et Hattingh, 1987). Crosse et Garrett (1970) avaient constaté également l'homogénéité phénotypique et la spécificité d'hôte de $P s \mathrm{pv}$ syringae et de $P s$ pv morsprunorum isolés sur arbres fruitiers en Grande-Bretagne, ce qui, pour ces auteurs, était le résultat d'une haute pression de sélection de la plante hôte et d'un environnement peu diversifié. La variabilité biochimique du pv persicae est limitée à quelques caractères 
biochimiques, et semble liée à l'origine géographique des souches (Luisetti et Gaignard, 1984b); cette homogénéité peut s'expliquer par l'étroite spécificité d'hôte de ce pathovar, une distribution très liée aux sols et au climat (Vigouroux et Huguet, 1980) et peut être par la relative «jeunesse» de ce germe dont la sélection sur pêcher n'a été observée que depuis une trentaine d'années.

Les caractères cytologiques et biochimiques de trois pathovars de $P$ syringae, présents en France sur plantes ligneuses, sont présentés dans le tableau IV.

\section{Caractères sérologiques et lysotypiques}

Les Pseudomonas possèdent un certain nombre de structures de surface : molécules qui peuvent être des antigènes et récepteurs pour les bactériophages; une variabilité est observée à ce niveau.
Plusieurs classifications des Pseudomonas phytopathogènes fluorescents, basées sur des caractères antigéniques, ont été proposées par Lovrekovich et al (1963), Otta et English (1971), Coléno (1973) et Patushenko et Simonovich (1979). Bien que ces auteurs n'aient travaillé ni avec les mêmes souches, ni avec les mêmes techniques de préparation des antigènes, leurs résultats sont convergents, soulignant l'existence d'antigènes communs chez certains pathovars ou des différences nettes entre d'autres pathovars. Par la technique d'immunodiffusion, Samson et Saunier (1987) sont parvenues à une conclusion similaire à partir des antigènes portés par le lypopolysaccharide de 12 pathovars de $P$ syringae. L'utilisation des anticorps monoclonaux devrait permettre de mieux différencier les pathovars, bien que Casano et al (1987) aient montré, dans un premier travail, que ces anticorps n'avaient qu'un intérêt partiel pour $P S$ pv syringae.

Tableau IV. Caractères cytologiques et biochimiques de 3 pathovars de $P$ syringae signalés sur plantes ligneuses (Lelliott et al, 1966; Hildebrand et Schroth, 1972; Luisetti et al, 1972; Bergey's Manual of Systematic Bacteriology 1984).

\section{Caractères}

Pspvsyringae Pspvmorsprunorum

Ps pvpersicae

Gram

Flagelles

Voie d'oxydation du glucose

Production pigment fluorescent/KB

Production pigment fluorescent/CSGA

Production de levane

Présence d'une oxydase

Présence d'une pectinase

Présence d'une arginine dihydrolase

Hypersensibilité sur Tabac

\section{Hydrolyse de la gélatine}

Hydrolyse de l'esculine

Réduction des nitrates

Utilisation du saccharose

Acidification / Alcalinisation de sources de carbone : méso-inositol

érythritol

sorbitol

$\mathrm{D}(-)$ tartrate

$\mathrm{L}(+)$ tartrate

DL-lactate

-
lophotriche
oxydative
+
+
+
-
-
-
+
+
+
-
+
+
+
+
+

lophotriche

oxydative

oxydative

$+$

$+$

$+$

$-$

$-$

$+$

-
-
-
+
+
$v$
+
-
+
-
$-$

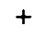

$+$

-

$-$

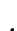

$-$

$-$

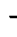

$+$

$-$

-

$v$ : variable. 
Les Pseudomonas sont connus pour être porteurs de prophages (ou phages tempérés). Perlasca, en 1960, n'a pas mis en évidence de phages spécifiques de souches en fonction de leur pathogénécité ou de phages lysant l'ensemble des souches. Crosse et Garrett (1963) ont testé la sensibilité de plus de 200 souches de Pseudomonas pathogènes ou saprophytes à 23 phages tempérés, isolés de $P s$ pv syringae et de $P s$ pv morsprunorum. Ils ont pu ainsi séparer $P s \mathrm{pv}$ syringae de $P s \mathrm{pv}$ morsprunorum mais aussi les souches du pv morsprunorum selon l'hôte d'origine. À partir d'échantillons de terre prélevés dans le vignoble champenois durant le printemps 1987, Luisetti et Gaignard (données non publiées) ont isolé des phages virulents présentant une activité lytique vis-à-vis de souches de $P s$ pv syringae et inactifs vis-àvis de souches de $P$ fluorescens isolés sur les plants de vigne des mêmes parcelles. Dans une synthèse sur les bactériophages, Billing et Garrett (1983), constatent que ceux-ci sont peu employés pour l'identification des bactéries phytopathogènes bien que certains d'entre eux soient hautement spécifiques.

\section{Caractères génétiques}

La valeur du GC\% (coefficient de Chargaff, pourcentage de guanine et de cytosine dans les acides nucléiques) de l'espèce $P$ syringae varie de 58 à $61 \%$ (Palleroni, 1984).

Comme chez beaucoup de bactéries, la présence de plasmides de poids moléculaire variable a été démontrée chez $P s$ pv syringae. Ces plasmides sont conjugatifs (Gonzales et al, 1984), et peuvent être porteurs de gènes de résistance aux antibiotiques et aux métaux lourds qui sont aussi transmissibles à d'autres bactéries. Le genre Pseudomonas est celui dans lequel Manceau (1984) a détecté le plus grand nombre de caractères de résistance aux antibiotiques et aux métaux lourds. II semble que ceuxci soient portés par le chromosome, mais l'auteur s'interroge sur le risque de transfert sur les plasmides de ces gènes de résistance. Sundin et al (1989), qui n'ont pas réussi à transférer un plasmide, porteur de la résistance au cuivre, de $P s$ pv syringae vers $P s$ pv morsprunorum, concluent à une incompatibilité génétique entre ces 2 pathovars à ce niveau. Ils pensent qu'il ne devrait pas y avoir de problème de différenciation, au niveau génétique, entre ces 2 pathovars.
Une relation entre la présence de plasmide et la production de syringomycine, toxine produite par $P s$ pv syringae, est une hypothèse formulée par Gonzales et Vidaver (1978). Cette hypothèse a été infirmée par Currier et Morgan (1983), par Gonzales et al (1984) et par Xu et Gross (1988a) qui ont démontré que des souches sans plasmide produisent toujours une toxine et que plusieurs gènes sont nécessaires pour la synthèse de celle-ci, ce qui pourrait expliquer le pouvoir pathogène sur une gamme d'hôtes. Xu et Gross (1988b) ont montré que la production de la syringomycine était réglée par les gènes syrA et syrB. D'après Gonzales et al (1984), le plasmide pCG jouerait un rôle dans la virulence de certaines souches de $P s$ pv syringae. Moor et Gross (1991) ont vérifié que la production de syringomycine, réglée par le gène syr $B$, était modulée par la perception de 2 classes de signaux moléculaires émis par la plante.

Les gènes hrp (hypersensitive reaction pathogenicity) qui contrôlent simultanément la pathogénèse de $P s \mathrm{pv}$ phaseolicola sur haricot et la réaction HR (hypersensibilité sur plantes non hôtes) ont été mis en évidence par Lindgren et al (1986). Boucher et al (1987), Ariat et Boucher (1989) ont également repéré chez $P$ solanacearum les gènes hrp et ils ont signalé l'existence de gènes $d s p$ (disease specific) qui contrôlent l'apparition des symptômes de la maladie sur plantehôte. L'existence des gènes hrp chez d'autres pathovars de l'espèce $P$ syringae, dont $P s$ pv syringae, a été vérifiée par Mills et Mukhopadyay (1990). Willis et al (1990) notent cependant que leur fréquence est faible pour ce pathovar. Ils ont isolé et caractérisé un mutant de $P s$ pv syringae incapable de former des lésions sur haricot. Ils ont aussi mis en évidence l'existence de gènes (nommés lemA, lesion modification) responsables de cette propriété.

\section{Production de toxine chez les Pseudomonas}

La première toxine phytobactérienne a été mise en évidence en 1925 par Johnson et Murwin chez $P s$ pv tabaci. II s'agit de la tabtoxine, dont la structure n'a été décrite qu'en 1971 par Stewart. Elle est également produite par $P s$ pv coronofaciens (Sinden et Durbin, 1970). C'est vers 1970 que débutent les travaux sur la toxine de $P$ $s$ pv syringae. Pour cette bactérie, 3 toxines sont signalées : la syringomycine identifiée, en 1968 , aux États-Unis, à partir d'un isolat pathogène du 
pêcher (de Vay et al, 1968) ; elle a été mise en évidence dans d'autres isolats provenant d'hôtes divers comme Prunus, Pyrus, Zea mays, Vigna sinensis. Garriga et al (1990) ont montré que la cystéine réglait la production de syringomycine. La deuxième, la syringotoxine, n'est observée que chez les souches pathogènes des Citrus (Gonzales et al, 1981). La troisième, la syringostatine, a été isolée et partiellement caractérisée par Isogai et al (1989) à partir de souches isolées de lilas au Japon.

La production d'une toxine par $P s$ pv phaseolicola soupçonnée dès 1950, n'a été étudiée sur le plan structural que récemment par Mitchell (1977). II a décrit la structure de la phaséolotoxine, produite par $P s$ pv phaseolicola, et responsable du halo chlorotique, symptôme typique observé sur haricot infesté par cette bactérie. La coronatine produite par plusieurs pathovars de $P$ syringae (Mitchell, 1982) provoque une hypertrophie des cellules de tubercules de pomme de terre (Sakai et al, 1979).

En 1983, Luisetti a mis en évidence que $P s p v$ persicae produisait une toxine possédant 2 propriétés importantes : antibiotique et phytotoxique. Barzic (1985) émet l'idée qu'il pourrait s'agir de plusieurs substances.

\section{APTITUDE ÉPIPHYTE DES P SYRINGAE}

Le cycle des bactéries appartenant à cette espèce est caractérisé, dans la plupart des cas, par une phase épiphyte (vie active des populations à la surface des organes de la plante) encadrant des périodes d'infection. Le cycle de $P s$ pv persicae proposé par Luisetti et al (1984) est présenté à titre d'exemple (fig 1).

\section{P syringae a une phase épiphyte}

En 1959, Crosse est le premier à démontrer que $P s$ pv morsprunorum, alors situé au rang d'espèce $P$ morsprunorum, organisme pathogène du cerisier, est présent à la surface de feuilles saines de cerisier. II s'agit là d'une observation essentielle pour l'épidémiologie des Pseudomonas phytopathogènes. Crosse suggère que ces bactéries pourraient constituer un inoculum capable d'être à l'origine de l'infection des tiges et des branches. En 1960, English et Davis, constatent le même phénomène avec $P s$ pv syringae sur feuilles de pêcher et d'aman-

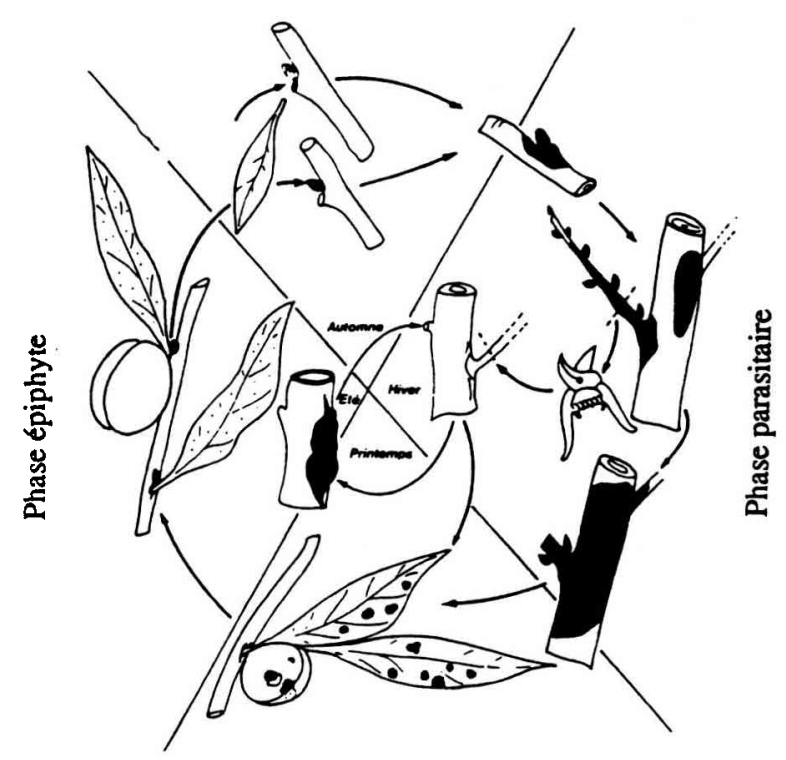

Fig 1. Cycle biologique de $P s$ pv persicae sur pêcher (d'après Luisetti et al, 1984).

dier, mais aussi sur fruits, sur brindilles et sur des plantes adventices dans les vergers. La colonisation des feuilles d'oranger et de citronnier par $P s$ pv syringae a été démontrée par Panagopoulos en 1966. Leben (1965) développe alors un nouveau concept selon lequel des bactéries phytopathogènes sont capables d'une phase épiphyte ou résidente sur des hôtes sains, au cours de laquelle elles se multiplient. La présence épiphyte de l'espèce $P$ syringae a été par la suite confirmée sur une multitude d'espèces végétales cultivées et adventices (tableau V).

Hirano et Upper (1983) tentent de définir ce qu'est une bactérie épiphyte. Les termes épiphytes, résidents, colonisateurs du phylloplan et bactéries de surface des plantes sont utilisés comme synonymes dans la littérature pour décrire les microrganismes capables de vivre à la surface des plantes. Ces auteurs ont finalement adopté une définition des bactéries épiphytes comme étant celles récupérées par lavage des parties aériennes de la plante. Cette définition simple, voire simpliste, ne permet pas de différencier bactérie "résidente" et bactérie "fortuite" décrites par Leben et al en 1968 pour distinguer les bactéries qui sont capables de se multiplier à la surface des feuilles de celles qui peuvent arriver sur une feuille par hasard sans pouvoir s'y multiplier et donc la coloniser. 
Tableau V. Plantes sur lesquelles a été mise en évidence l'aptitude épiphyte de bactéries appartenant à l'espèce $P$ syringae.

\begin{tabular}{|c|c|c|}
\hline Espèce, pathovar & Auteurs & Plantes \\
\hline$P$ spv glycinea & $\begin{array}{l}\text { Daft et Leben, } 1972 \\
\text { Leben et al, } 1968 \\
\text { Mew et Kennedy, } 1971\end{array}$ & $\begin{array}{l}\text { Soja } \\
" 1\end{array}$ \\
\hline P s pv lachrymans & $\begin{array}{l}\text { de Lange et Leben, } 1970 \\
\text { Yamaka et al, } 1980\end{array}$ & $\begin{array}{l}\text { Concombre } \\
"\end{array}$ \\
\hline$P s p v$ morsprunorum & $\begin{array}{l}\text { Bordjiba et Prunier, } 1991 \\
\text { Crosse, 1959; 1966; } 1971 \\
\text { Crosse et Garrett, 1970 } \\
\text { Ercolani, 1969a; 1969b } \\
\text { Latorre et Jones, 1979a } \\
\text { Prunier et Cotta, 1985 } \\
\text { Roos et Hattingh, 1983; 1986a } \\
\text { Sobiczewski, } 1978 \\
\text { Sundin et al, } 1988\end{array}$ & $\begin{array}{l}\text { Abricotier } \\
\text { Cerisier } \\
\text { Cerisier et prunier } \\
\text { Cerisier } \\
" \\
\text { Abricotier } \\
\text { Cerisier } \\
" \\
"\end{array}$ \\
\hline Pspv papulans & Burr et Katz, 1984 & Pommier \\
\hline$P$ s pv persicae & $\begin{array}{l}\text { Gardan et al, } 1972 \\
\text { Luisetti et Drouhard, } 1981 \\
\text { Luisetti et Gaignard, 1984a } \\
\text { Luisetti et al, } 1984 \\
\text { Luisetti et al, } 1992 \\
\text { Prunier et Luisetti, } 1983 \\
\text { Young, } 1988\end{array}$ & $\begin{array}{l}\text { Pêcher } \\
" 1 \\
" 1 \\
" 1 \\
" \\
\text { Pêcher, prunier du Japon }\end{array}$ \\
\hline Pspv pisi & Samson et al, 1988 & Pois protéagineux \\
\hline$P$ spv syringae & $\begin{array}{l}\text { Anderson et al, } 1981 \\
\text { Baca et Moore, } 1987 \\
\text { Baca et al, } 1987 \\
\text { Bordjiba et Prunier, } 1991 \\
\text { Burr et Katz, } 1984 \\
\text { Cameron, } 1962 \\
\text { Cameron, } 1970 \\
\text { Canfield et al, } 1986 \\
\text { Constantinidou et al, } 1991 \\
\text { Cottin, } 1989 \\
\text { Endert et Ritchie, } 1984 \\
\text { English et Davis, } 1960 \\
\text { Ercolani, 1969a; } 1969 \mathrm{~b} \\
\text { Ercolani et al, 1974 } \\
\text { Fryda et Otta, } 1978 \\
\text { Gardan et al, } 1989 \\
\text { Gross et al, 1983; } 1984 \mathrm{a} \\
\text { Hattingh et al, } 1989 \\
\text { Hirano et Upper, } 1989 \\
\text { Hirano et al, } 1985 \\
\text { Hirano et al, } 1988 \\
\text { de Lange et Leben, } 1970\end{array}$ & $\begin{array}{l}\text { Bégonia, œillet d'inde, souci, zinnia } \\
\text { Plantes adventices } \\
\text { Plantes de pépinières } \\
\text { Abricotier } \\
\text { Pommier } \\
\text { Cerisier } \\
\text { Merisier } \\
\text { Lilas, magnolia, tilleul, peuplier, poirier, pommier } \\
\text { Citrus } \\
\text { Laurier palme } \\
\text { Pêcher } \\
\text { Pêcher, amandier, plantes adventices } \\
\text { Cerisier, poirier } \\
\text { Haricot } \\
\text { Blé } \\
\text { Laurier palme } \\
\text { Poirier, pommier, Prunus spp } \\
\text { Poirier, pommier, Prunus spp } \\
\text { Haricot } \\
\text { Avoine } \\
\text { Haricot } \\
\text { Haricot et concombre }\end{array}$ \\
\hline$P$ s pv syringae & $\begin{array}{l}\text { Latorre et Jones, } 1979 a \\
\text { Latorre et Jones, } 1979 \mathrm{~b} \\
\text { Latorre et al, } 1985 \\
\text { Leben et al, } 1970\end{array}$ & $\begin{array}{l}\text { Cerisier } \\
\text { Poirier, plantes adventices } \\
\text { Cerisier } \\
\text { Haricot }\end{array}$ \\
\hline
\end{tabular}


Tableau V. Suite

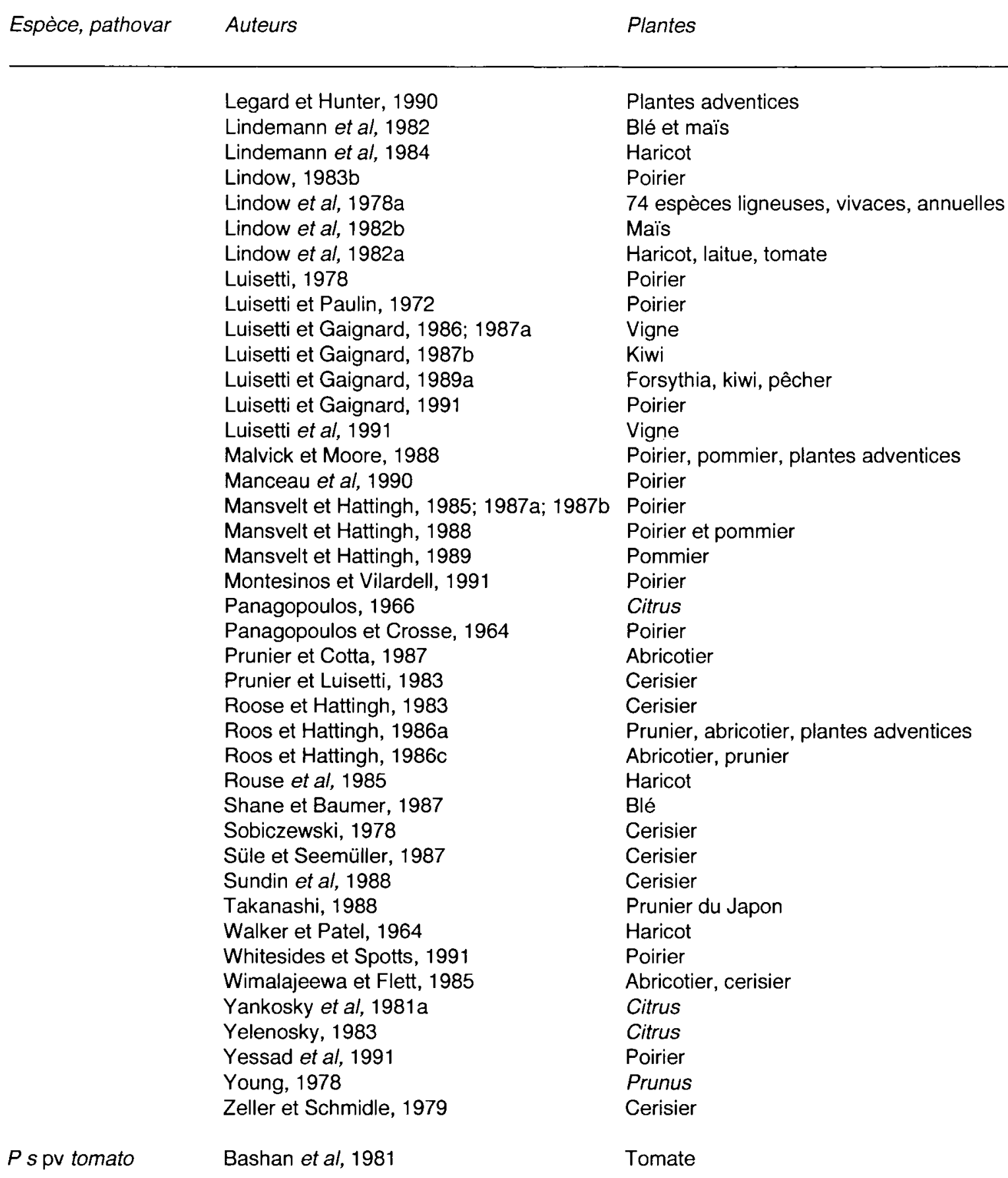

Roos et Hattingh (1983) ont suivi expérimentalement au microscope à balayage la colonisation des feuilles de cerisier par $P$ s pv morsprunorum. Peu de temps (15 min) après la pulvérisation de la suspension bactérienne, de très nombreuses bactéries apparaissent réparties au hasard sur la feuille, mais elles disparaissent ensuite ( $3 \mathrm{j}$ ) pour la plupart. Cette baisse de population est égale- ment observée par Young (1978) et par Prunier et Luisetti (1983). II faut attendre le $6 \mathrm{e}$ j pour voir réapparaître des amas bactériens importants qui sortent de certains stomates colonisés. Ces bactéries vont permettre de poursuivre la colonisation de nouveaux organes ou servir d'inoculum aux moments opportuns de la contamination (cicatrices foliaires en automne). Roos et Hattingh 
(1983) reprennent le concept émis par Young en 1978, de multiplication dans les cavités stomatiques qui seraient des infections "sub-cliniques" générant, sous des conditions favorables, des populations bactériennes importantes relarguées par la suite à la surface de la feuille. Yamaka et al (1980), Bashan et al (1981) ont constaté que la colonisation des stomates et de leurs abords était importante dans le développement et la dissémination de l'infection par les bactéries phytopathogènes épiphylles.

\section{Abondance des populations}

De nombreux travaux ont porté sur le sujet (Hirano et Upper, 1990) ; chez le poirier par exemple, Ercolani (1969a, b) montre que $P s$ pv syringae se maintient durant l'hiver dans les bourgeons. Luisetti et Paulin (1972) confirment cette observation sur poirier et dénombrent au printemps jusqu'à $10^{6}$ bactéries par fleur apparemment saine. Mansvelt et Hattingh (1988) isolent jusqu'à $10^{7} P$ syringae par fleur de poirier et $10^{5}$ par fleur de pommier en Afrique du Sud. Cette différence de niveaux de population bactérienne entre poirier et pommier est également constatée par Malvick et Moore, en 1988, dans l'État d'Orégon. En Espagne, sur bourgeon de poirier en hiver, Montesinos et Vilardell (1991) dénombrent de $10^{3}-10^{8} P s$ pv syringae/g poids frais.

\section{Influence des conditions climatiques}

La distribution et la fréquence des Pseudomonas épiphytes sur merisier ont été étudiées par Cameron (1970), qui montre que l'humidité et la température ont une influence sur la multiplication des bactéries. Hirano et Upper $(1985,1990)$ notent qu'après une période sèche les niveaux baissent, et augmentent en revanche sous des conditions humides. En France, sur pêcher et poirier, les niveaux de population sont les plus élevés durant les printemps et automne humides (Gardan et al, 1972; Luisetti et Paulin, 1972). Sur kiwi, arrosé sur frondaison, Luisetti et Gaignard (1987b) dénombrent en été des populations élevées de Pseudomonas.

Sur plantes annuelles telles que le soja (Leben et al, 1968) et le haricot (Leben et al, 1970), l'existence d'une phase résidente de $P s$ pv glycinea et de $P s$ pv syringae est signalée sur les bourgeons ; le niveau des populations est fonction du taux d'humidité. Sur feuilles de semis de haricot et sur bourgeons de concombre conduits sous des conditions humides, de Lange et Leben (1970) confirment l'aptitude à la vie épiphyte de $P s$ pv syringae et de $P s$ pv lachrymans.

\section{Conservation et dissémination de la bactérie}

Des éléments liés à la plante et des facteurs de l'environnement interviennent dans la conservation de l'inoculum et dans sa dissémination. De nombreux sites de conservation ont été signalés (tableau VI).

Sur haricot, Walker et Patel (1964) et, sur soja, Daft et Leben (1972) ont vérifié que l'inoculum pouvait se disséminer de proche en proche par les éclaboussures de la pluie et par le vent. Lindemann et al (1982) ont détecté des bactéries de l'espèce $P$ syringae en suspension dans l'air au-dessus de cultures de maïs, blé, pois, haricot et luzerne par jour ensoleillé. Gaignard (1992) constate le passage de plants à plants sur la vigne issue d'in vitro, en cours d'acclimatation, dans une cellule climatisée en l'absence d'agitation de l'air ambiant. En 1990, Constantinidou et al ont isolé d'eau de pluie des bactéries appartenant à l'espèce $P$ syringae.

La dissémination de $P s$ pv persicae à partir d'un foyer initial de 16 arbres (pêchers de la variété Redwing) situés au centre d'une parcelle d'1 ha et contaminés artificiellement à l'automne a été suivie (Luisetti et Drouhard, 1981) ; un an après, sans une seule intervention de l'homme, la bactérie était présente, sans qu'il y ait présence de symptômes, à la surface des feuilles de $64 \%$ des arbres, répartis au hasard dans la parcelle.

\section{La surface de la feuille, support de la bactérie}

Le mot surface, pose quelques problèmes conceptuels. Young (1978) pense que $P s$ pv syringae se maintient dans des sites de protection sur ou dans les feuilles de Prunus. On sait qu'il peut y avoir des échanges dynamiques entre la population externe vivant à la surface des feuilles et une population «interne" cachée dans les cavités sous-stomatiques, comme l'ont observé Roos et Hattingh (1983) sur feuille de cerisier et Hattingh et al (1989) sur feuille de pommier. Après lavage de feuilles de pêcher ne présentant 
Tableau VI. Sites de conservation de $P$ syringae.

Sites Auteurs

Bourgeons dormants

Chambres sous-stomatiques

Chancres et lésions

Débris végétaux

Graines et noyaux

Plantes adventices

et plantes relais

Scions pépinières

Sol

\author{
Burr et Katz, 1984 \\ Cameron, 1962 \\ Dowler et Weaver, 1975 \\ Endert et Ritchie, 1984 \\ Ercolani, 1969a; 1969b \\ Hattingh et al, 1989 \\ Kagiwata et al, 1990b \\ Leben, 1972 \\ Luisetti et Paulin, 1972 \\ Luisetti et al, 1984 \\ Luisetti et Gaignard, 1987b \\ Montesinos et Vilardell, 1991 \\ Roos et Hattingh, 1986b \\ Sundin et al, 1988 \\ Hattingh et al, 1989 \\ Crosse, 1955 \\ Kagiwata et al, 1990b \\ Latorre et al, 1985 \\ Otta et English, 1970 \\ Prunier et al, 1970a \\ Hoitink et al, 1968 \\ Legard et Hunter, 1990 \\ Fryda et Otta, 1978 \\ Hattingh et al, 1989 \\ Karaca et Demir, 1988 \\ Leben, 1981 \\ Mc Carter et al, 1983 \\ Walker et Patel, 1964 \\ Baca et Moore, 1987 \\ English et Davis, 1960 \\ Hirano et Upper, 1985 \\ Latorre et Jones, $1979 b$ \\ Legard et Hunter, 1990 \\ Mc Carter et al, 1983 \\ Malvick et Moore, 1988 \\ Roos et Hattingh, 1986a \\ Waissbluth et Latorre, 1978 \\ Dowler et Petersen, 1967 \\ Luisetti et al, 1992 \\ Wimalajeeva et Flett, 1985 \\ Stout, 1960
}

aucun symptôme, Luisetti et Gaignard (1984a) ne récupèrent pas toutes les bactéries. En effet, après un broyage consécutif à ce lavage, ils récupèrent de nouvelles bactéries qui n'ont pas été "décrochées" par le premier traitement. Ils émettent l'idée de l'existence de microlésions dans lesquelles se multiplieraient les Pseudomonas.

La surface de la feuille est plutôt un environnement hostile pour les microrganismes. Les fluctuations de température, les rayons ultra-violets, les périodes de dessiccation sont des éléments défavorables (Henis et Bashan, 1986). Luisetti et Gaignard (1984a) ont montré que les bactéries se maintenaient essentiellement sur les pousses basses, la face inférieure de feuilles et au centre des pêchers. Sur pousses de pommier et de poirier, Hattingh et al (1989) constatent le même phénomène. Les rayons ultra-violets et la dessiccation éliminent probablement les bactéries situées sur les parties de l'arbre exposées 
au soleil. Hattingh et al (1989) émettent l'hypothèse que $P$ syringae survit, en période chaude et sèche, dans les chambres sous-stomatiques.

La dynamique des bactéries durant la phase épiphyte peut être également perturbée par des bactéries saprophytes et par des champignons (Crosse, 1971; Gaignard, 1992). Plusieurs Pseudomonas pathogènes peuvent également cohabiter à la surface des organes d'arbres fruitiers (Latorre et Jones, 1979a; Luisetti et Gaignard, 1987b). La dynamique est la résultante d'un ensemble de phases : croissance, survie, mortalité, émigration et immigration influencées par les conditions chimiques, biologiques, microbiologiques et physiques de l'environnement de la surface de la feuille. Les conditions citées évoluant continuellement, les variations microbiologiques, tant en quantité qu'en qualité, sont très importantes d'un moment à l'autre, que ce soit d'heure en heure, de jour en jour ou de semaine en semaine (Blakeman, 1985; Mc Innes et al, 1988; Hirano et Upper, 1989). Kinkel et al (1987) comparent la colonisation d'une feuille par des champignons à celle d'une île par des macrorganismes. Compte tenu de la similarité des phénomènes d'immigration, d'émigration et de sélection, on peut certainement étendre aux bactéries ce concept de colonisation.

La variabilité de la répartition des populations épiphytes au niveau de l'arbre a été étudiée, après une pulvérisation homogène de $P s$ pv persicae réalisée au printemps (Prunier et Luisetti, 1983). Les analyses individuelles de feuilles montrent une grande hétérogénéité de la distribution de l'inoculum. Certaines feuilles demeurent totalement indemnes. Cette variabilité se retrouve au niveau de la feuille car, après une pollution artificielle homogène du cerisier par $P S$ pv morsprunorum, les bactéries sont groupées en amas localisés en un nombre réduit de sites. Le même phénomène a été constaté sur feuilles de pêcher après pollution naturelle ou artificielle par $P s$ pv persicae. Ceci a amené les auteurs à considérer la phase épiphyte comme une phase d'infection atténuée n'aboutissant pas à l'expression de symptômes visibles. Dans une étude sur les premières étapes de la colonisation de feuilles de cerisier par $P s$ pv syringae, ils ont montré qu'il y a d'abord une courte phase de sélection ( $2 \mathrm{j}$ ), suivie d'une croissance accélérée interrompue plus ou moins rapidement (2-19 j) par l'action d'un facteur qui pourrait être lié à l'hôte. En 1978, Young, posait déjà la question de la nature de l'interaction bactérie épiphyte/plante. À propos de l'écologie de l'espèce $P$ syringae, Hi- rano et Upper (1985) précisent que chaque feuille constitue un écosystème variable et dynamique, ce qui peut expliquer les variations intraplante très importantes. Hirano et al (1982) ont constaté que la distribution des populations de Pseudomonas épiphytes était log-normale. Ils ont observé un facteur de variation entre feuilles pouvant atteindre 100 à 1000. Les stratégies de lutte et en particulier de lutte biologique doivent tenir compte de cet état.

Sur vitroplant de vigne, Gaignard (1992) constate que toutes les feuilles d'un même vitroplant ne sont pas colonisées et que la bactérie ne se maintient pas systématiquement sur ce matériel malgré des conditions abiotiques favorables. II conclut que cette phase n'est pas un phénomène passif et que les facteurs abiotiques ne sont pas les seuls déterminants de cette dynamique épiphyte.

Les éléments nutritionnels ou inhibiteurs présents sur une feuille exercent une pression sélective sur le développement et sur la capacité d'adaptation des microrganismes qui l'habitent. Les niveaux de population bactérienne refléteraient la composition nutritionnelle et les conditions de l'environnement de l'habitat selon Gross et al (1984a). II s'agit de substances carbonées, azotées selon Morris et Rouse (1985). Hirano et Upper (1990) supposent que la bactérie induit des mécanismes entraînant la sécrétion d'éléments nutritionnels par la feuille, phénomène constaté dès 1978 par Young sur feuille de Prunus, puis en 1983 par Ross et Hattingh sur feuille de cerisier après installation artificielle de $P s$ pv morsprunorum. Mansvelt et Hattingh (1987a) observent, en microscopie électronique à balayage, la présence subséquente de bactéries et de matériel extracellulaire dans des sites particuliers de la feuille de poirier. La population bactérienne augmentant, la concentration de substances associées augmente ; celles-ci deviendraient alors toxiques pour la plante et occasionneraient des microlésions par lesquelles pourraient pénétrer les bactéries épiphytes (Hirano et Upper, 1990).

\section{Spécificité d'hôte}

Certains pathovars sont spécifiques d'une seule espèce végétale, comme le pathovar persicae (Prunier et al, 1970a) alors que d'autres, comme les pathovars syringae et morsprunorum, sont signalés épiphytes et pathogènes sur plusieurs plantes. 
Un degré de spécificité d'hôte est une hypothèse émise par certains auteurs. Ercolani (1969a) a démontré qu'une souche de $P s$ pv morsprunorum isolée sur cerisier et qu'une souche de $P s$ pv syringae isolée sur poirier colonisaient seulement les feuilles de leur hôte respectif quand elles étaient installées artificiellement en dépit de l'apparente capacité du pathovar syringae à se maintenir sur les plantes adventices comme l'ont montré Latorre et Jones (1979b). À partir d'un travail mené avec des souches de $P s$ pv syringae isolées sur haricot et sur poirier, Manceau et Chevron (1989) constatent que les souches s'installent de façon préférentielle à la surface de leur hôte homologue. Yessad et al (1991) émettent l'hypothèse que, sur feuille de poirier, la pathogénie des souches de $P s$ pv syringae pourrait être un facteur majeur dans la survie épiphyte de la bactérie en conditions sèches. Après installation artificielle de la bactérie sur soja, Mew et Kennedy (1971) ob-servent que le taux d'inoculum augmente considérablement sur les variétés sensibles alors que sur les variétés résistantes il diminue à partir du 7 e jour. Crosse et Garrett (1970) ont observé le même phénomène sur cerisier. Une observation totalement opposée a été faite par Roos et Hattingh (1983) sur cerisier dont la variété Black Tartarian, considérée comme la plus résistante au chancre bactérien, est capable d'héberger des populations importantes de $P s$ pv morsprunorum. Gaignard (1992) a constaté sur vitroplant de kiwi la bonne multiplication épiphyte d'une souche de $P$ s pv syringae provenant de vigne.

\section{ACTIVITÉ GLAÇOGĖNE DES P SYRINGAE}

\section{Les noyaux glaçogènes}

L'eau extra pure peut être maintenue en état de surfusion jusqu'à $-40{ }^{\circ} \mathrm{C}$. Mais dans la nature l'eau n'est pas pure. Elle est en contact avec de nombreuses particules et notamment des noyaux de cristallisation ou noyaux glaçogènes. Ces noyaux provoquent une rupture de surfusion de l'eau à des températures négatives, plus ou moins proches de $0^{\circ} \mathrm{C}$.

Jusqu'à ces dernières années la formation de glace au niveau du végétal constituait une énigme. En effet, les différents noyaux de cristallisation dont on connaissait l'existence (particules minérales, poussières...) ne sont très actifs que pour des températures inférieures à $-10{ }^{\circ} \mathrm{C}$
(Schnell et Vali, 1976). Certains cristaux de composés organiques sont aussi actifs dans le déclenchement de la cristallisation à des températures de l'ordre de $-5^{\circ} \mathrm{C}$. II s'agit d'acides aminés (Power et Power, 1962; Barthakur et Maybank, 1963; Parungo et Lodge, 1967), de protéines (Zettlemoyer et al, 1961), de terpènes (Rosinski et Parungo, 1966). Ils sont actifs seulement sous la forme cristalline (Parungo et Lodge, 1965). On expliquait ainsi difficilement la formation des gelées survenant à des températures aussi "chaudes" que $-2{ }^{\circ} \mathrm{C}$ à $-4^{\circ} \mathrm{C}$. Dès 1957, Soulage soupçonne l'existence de noyaux de cristallisation d'origine biologique, mais ce n'est qu'en 1973 que Fresh la démontre. La source biologique de cristallisation est isolée à partir de feuilles d'aulne en décomposition. II s'agit d'une souche bactérienne qui constitue un excellent initiateur de prise en glace à partir de $-2{ }^{\circ} \mathrm{C}$. Son identité est révélée en 1974 par Maki et al; il s'agit d'une bactérie de l'espèce $P$ syringae. Vali et al estiment en 1976 que ce type de microrganisme constitue les noyaux de cristallisation les plus efficaces dans la nature, mis à part la glace elle-même.

\section{Les bactéries glaçogènes}

Cinq espèces bactériennes sont signalées comme aptes à provoquer la rupture de surfusion de l'eau. II s'agit principalement de $P$ syringae ( $80 \%$ des souches de certains pathovars), $P$ viridiflava ( $30 \%$ des souches) et Xanthomonas campestris pv translucens et plus occasionnellement de quelques souches de 2 espèces saprophytes, $P$ fluorescens et Erwinia herbicola (Maki et al, 1974; Arny et al, 1976; Vali et al, 1976; Hirano et al, 1978; Lindow et al, 1978a, b; Maki et Willoughby, 1978; Paulin et Luisetti, 1978; Yankofsky et al, 1981a; Lindow, 1983a; Gross et al, 1983; Kim et al, 1987).

À partir de lavages d'échantillons prélevés sur 95 espèces de plantes ligneuses, Lindow et al (1978a) ont isolé sur 74 d'entre elles des souches glaçogènes des espèces $P$ syringae et $E$ herbicola. Seuls les conifères ne semblent pas porteurs de ces bactéries. À partir de 387 souches de la collection française de bactéries phytopathogènes (Angers), Paulin et Luisetti (1978) constatent que $87 \%$ des souches de $P S$ pv syringae isolées d'arbres fruitiers sont glaçogènes alors que le pourcentage est très faible pour les souches isolées de céréales. Baca et al (1987) isolent de différentes espèces végétales 
ligneuses conduites en pépinière une proportion importante de souches glaçogènes appartenant à l'espèce $P$ syringae. Le même constat est fait par Baca et Moore (1987) sur plantes adventices, en pépinière, et par Luisetti et Gaignard (1987a) sur vigne.

\section{Rôle des bactéries glaçogènes et de l'eau dans le gel des plantes}

La présence et le rôle des bactéries glaçogènes dans la rupture de l'état de surfusion de l'eau dans la plante et à sa surface et dans le développement de dégâts de gel et/ou de bactériose ont été vérifiés sur de nombreuses plantes herbacées ou ligneuses. Depuis la mise en évidence du phénomène, de nombreux travaux ont permis de vérifier le rôle des bactéries glaçogènes sur les plantes (tableau VII). En conditions expérimentales, Paulin et Luisetti (1978) sur tabac; Anderson et al (1981) sur plantes florales herbacées; Yankosky et al (1981a) et Yelenosky (1983) sur Citrus; Anderson et al (1982) sur soja et sur tomate; Lindow et al (1982a) sur concombre, tomate et citrouille; Lindow et al (1982b) sur maïs; Andrews et al (1983) sur pê-

Tableau VII. Plantes sur lesquelles ont été mises en évidence la présence et l'action de Pseudomonas glaçogènes (gel et/ou bactériose).

Anderson, 1988

Anderson et Asworth, 1985

Anderson et al, 1981

Anderson et al, 1982

Andrews et al, 1983

Arny et al, 1976

Asworth et Davis, 1984

Constantinidou et al, 1991

Gaignard, 1992

Goto et al, 1988

Gross et al, 1983

Gross et al, 1984b

Hirano et Upper, 1989

Hirano et al, 1985

Kim et al, 1989

Lindow, 1979

Lindow, 1983b

Lindow et Connel, 1984

Lindow et Panopoulos, 1991

Lindow et al, 1982a

Lindow et al, 1982b

Luisetti, 1978

Luisetti et Gaignard, 1987a; 1989b

Luisetti et Gaignard, 1987b

Luisetti et Gaignard, 1989a

Luisetti et al, 1991

Paulin et Luisetti, 1978

Proesbting et al, 1982

Prunier et Bordjiba, 1991

Samson et al, 1988

Süle et Seemüller, 1987

Weaver et al, 1981

Whitesides et Spotts, 1991

Yankofsky et al, 1981a

Yelenosky, 1983
Tomate

Bégonia, œillet d'inde, souci, zinnia

Soja, tomate

Cerisier et pêcher

Maïs

Pêcher

Citrus

Vitroplants de vigne, lilas et kiwi

Thé

Poirier, pommier et Prunus spp

Prunus spp

Haricot

Avoine

Maïs

Pomme de terre

Poirier

Amandier

Pomme de terre

Concombre, citrouille, tomate, orge

Maïs

Poirier

Vigne

Kiwi

Forsythia, kiwi, pêcher

Vigne

Tabac

Poirier, Prunus spp

Abricotier

Pois protéagineux

Cerisier

Pêcher

Poirier

Citrus 
cher et cerisier; Lindow (1983b) sur poirier; Gross et al (1984b) sur Prunus spp; Hirano et al (1985) sur avoine; Anderson et Asworth (1985) et Anderson (1988) sur tomate; Luisetti et al (1991) sur vigne ont vérifié que la présence d'une population bactérienne glaçogène engendrait une élévation de la température de rupture de surfusion.

La rupture de la surfusion de l'eau peut être provoquée par d'autres causes. Dans tous les cas, la cristallisation débute à la surface du végétal et colonise l'intérieur des tissus par les stomates et les blessures (Burke et al, 1976). Sur haricot, Carry et Lindow (1986) ont mis en évidence que l'eau présente à la surface des organes intervenait également dans l'initialisation de la cristallisation. Sur soja, Hanyu et al (1986) observent que, sur feuille sèche, la rupture de surfusion se produit à une température plus froide que sur feuille humide. Le rôle de l'humidité de surface a été vérifié sur pêcher et sur cerisier (Andrews et al, 1983).

Plusieurs chercheurs émettent des réserves quant au rôle des bactéries glaçogènes et pensent que d'autres noyaux présentent une capacité plus performante de cristallisation. $\dot{A}$ partir d'expérimentations menées sur des pêchers conduits en plein champ, Ashworth et al (1985b) mettent en évidence des températures de rupture de surfusion de l'ordre de $-0,6^{\circ}$ à $-2,6^{\circ} \mathrm{C}$ mais n'isolent pas de bactéries. Sur pousses de pêcher prélevées en Virginie de l'Ouest, Anderson et al (1987) concluent que les bactéries glaçogènes ne sont pas les premiers noyaux de cristallisation. Ashworth et al (1985a), Gross et al (1984b; 1988) suspectent également l'existence d'autres noyaux, non bactériens, intrinsèques aux tissus des Prunus. En 1965, Liegel soulignait déjà la complexité des phénomènes intervenant dans la sensibilité des plantes au gel : teneur en eau, état du cytoplasme et modifications chimiques causées et commandées par l'activité des enzymes. Le rôle de l'eau contenue dans les bourgeons dans la modification du seuil de gélivité a été vérifiè chez l'amandier, le pêcher, le pommier et la vigne par Hewett et al (1978). $\dot{A}$ partir d'observations réalisées sur vigne au printemps en Champagne, Itier et al (1991) concluent que le stade phénologique du bourgeon et le mouillage sont des variables déterminantes, tandis que l'action des bactéries est beaucoup plus ténue et difficile à interpréter. Sur vigne, cultivée en conteneurs et en conditions contrôlées, Luisetti et al (1991) ont démontré qu'à niveau égal de population bactérienne la rupture de surfusion se produit en moyenne à des températures "plus chaudes" sur les organes plus chargés en "eau libre» (fig 2). Ces auteurs concluent que, si la teneur en eau et la teneur en bactéries glaçogènes, $P s \mathrm{pv}$ syringae en particulier, sont des éléments qui interviennent dans la rupture de surfusion de la vigne, d'autres éléments non facilement identifiables pourraient intervenir également.

Dans la mesure où le rôle des bactéries glaçogènes est confirmé et précisé sur plantes conduites en plein champ, on peut envisager de maintenir les populations en dessous d'un seuil de nuisibilité par application d'antibactériens. Des études doivent être menées pour chaque espèce végétale, et dans différentes conditions d'environnement. Sur vigne, Luisetti et Gaignard (1989b) pensent que cette lutte antibactérienne pourrait compléter les moyens classiquement utilisés dans la lutte antigel. En revanche, Cody et al (1987) rejettent cette voie de lutte sur poirier : après abaissement des populations bactériennes glaçogènes, ils constatent toujours la rupture de surfusion dès $-2{ }^{\circ} \mathrm{C}$. Ces résultats sur arbres fruitiers sont contradictoires avec ceux obtenus en 1982 par Lindow. Ceci montre la complexité du phénomène de la rupture de surfusion au niveau des plantes.

\section{Mécanismes d'action}

Plusieurs éléments interviennent dans la capacité de prise en glace d'une souche bactérienne donnée. Yankofsky et al (1981b) ont classé en 3

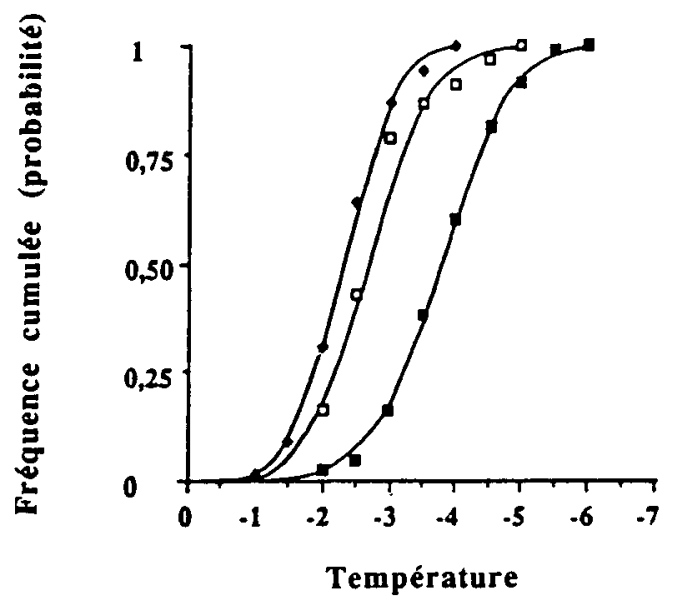

Fig 2. Fréquence cumulée des températures de rupture de surfusion des bourgeons (stades 3-5 et 7-9 cumulés). Effet des différents traitements : $\bullet$ plants arrosés la veille "bactérisés" et "non bactérisés"; $\square$ plants "secs" et "bactérisés" présentant $10^{6}$ bactéries par bourgeon; plants "secs" présentant $10^{3}$ bactéries par bourgeon (d'après Luisetti et al, 1991). 
groupes les souches bactériennes au niveau de leur pouvoir glaçogène, groupe 1 : actives entre $-2^{\circ}$ et $-4{ }^{\circ} \mathrm{C}$; groupe 2 : actives entre $-5^{\circ}$ et $-7^{\circ} \mathrm{C}$; groupe 3 : actives entre $-8^{\circ}$ et $-10^{\circ} \mathrm{C}$. Des facteurs extérieurs tels que le milieu de culture, la température d'incubation influencent le nombre d'unités de prise en glace présentes dans la population bactérienne in vitro (Luisetti et Gaignard, 1989b; Sikyta et al, 1989; Cochet et al, 1991; Pooley et Brown, 1991).

Les gènes déterminant l'activité glaçogène ont été clonés à partir de plusieurs souches de $P S$ $\mathrm{pv}$ syringae (gènes inaZ et iceC) (Orser et al, 1985; Green et Warren, 1985) : de $P$ fluorescens (gène inaW) (Warren et al, 1986) et d'E herbicola (Orser et al, 1985) : il s'agit d'un fragment d'ADN d'environ $7,5 \mathrm{~kb}$, codant pour une protéine de $180 \mathrm{kDa}$. Orser et al (1983) ont obtenu un mutant non glaçogène par délétion de ce gène. Corotto et al (1986), à partir d'une souche de $P$ fluorescens, ont transféré le gène ice dans Escherichia coli, qui est alors devenu glaçogène.

La protéine correspondant à ce «gène du gel» a été étudiée par Green et Warren (1985). Elle est composée de 1200 acides aminés. Warren et Corotto (1989) y ont mis en évidence, par extrapolation à partir des séquences de nucléotides des 3 gènes codant pour l'activité glaçogène, une séquence commune qui aurait un rôle important dans la nucléation. Lindow et al (1989) localisent la protéine au niveau de la membrane externe de la bactérie. Wolber et Warren (1986) proposent une structure de la protéine glaçogène et suggèrent que celle-ci peut être identique à la structure de la glace. Welch et Speidel (1989) ont observé des sites à la surface de la bactérie. Sur des souches glaçogènes d'E herbicola, Phelps et al (1986) ont montré que des vésicules (petits bourgeonnements de la paroi), bien que dépourvues de toute capacité de multiplication, sont porteuses de la plus grande part de l'activité glaçogène de cette espèce. II semble que l'espèce $P$ syringae ne soit pas capable de former de telles vésicules.

L'existence d'une liaison entre le pouvoir glaçogène et la présence d'un substrat, le phosphatidylinositol, a été démontré par Kozloff et al (1984).

Le pouvoir glaçogène des bactéries a aussi été utilisé dans le cadre d'essais de déclenchement de formation de la pluie (Levin et al, 1987), de congélation de produits alimentaires (Watanabe et Arai, 1987) et de fabrication de neige artificielle (Goodnow et al, 1990).

\section{POUVOIR PATHOGĖNE DES P SYRINGAE}

\section{Rôle de la phase épiphyte de P syringae dans le cycle biologique}

Le cycle des bactéries appartenant à cette espèce est caractérisé, dans la plupart des cas, par une phase épiphyte encadrant des périodes d'infection (fig 1). Ces populations épiphytes constituent une source d'infection pour les plantes. L'action pathogène de l'espèce $P$ syringae a été étudiée sur de nombreuses plantes ligneuses, plantes sur lesquelles cette espèce bactérienne entraîne des dommages importants, comme en témoigne le tableau II.

La réussite de l'infection est fonction de la qualité et de la quantité de l'inoculum, du niveau de sensibilité de la plante au moment de la pénétration et des conditions d'environnement (Henis et Bashan, 1986; Young, 1991; Whitesides et Spotts, 1991). À une phase épiphyte succède une phase pathogène et réciproquement. Le pêcher, l'abricotier, le prunier ne sont sensibles que durant le repos hivernal et lors des printemps humides. Sur poirier, sur cerisier, sur kiwi, les dégâts n'apparaissent au printemps qu'après des coups de gel (Panagopoulos et Crosse, 1964; Zeller et Schmidle, 1979; Mansvelt et Hattingh, 1987a; Luisetti et Gaignard, 1987b; 1991; Whitesides et Spotts, 1991). On pourrait d'ailleurs considérer ces bactéries comme des germes "occasionnels", compte tenu de ces observations et des résultats obtenus par Luisetti et Gaignard (1989a) sur plante en développement et par Klement et al (1972) et Vigouroux (1974) sur plante en repos végétatif.

La quantité d'inoculum et le moment de la pénétration de $P s$ pv morsprunorum par les plaies pétiolaires de cerisier conditionnent l'infection (Crosse, 1956). Gardan et al, en 1971, dans une étude sur les variations de l'inoculum de $P s \mathrm{pv}$ persicae présent sur les feuilles de pêcher à l'automne, concluent qu'il y a une relation entre le nombre de bactéries présentes à la surface des feuilles et le nombre de nécroses observées durant l'hiver, dans la mesure où les conditions d'environnement sont favorables à la maladie. L'incidence de la concentration d'inoculum sur le temps d'incubation, après infection artificielle par blessure, explique en partie l'échelonnement de l'apparition des nécroses dans les conditions naturelles (Luisetti et al, 1973b). Selon Ercolani et Vannela (1986), le temps de réponse est inver- 
sement proportionnel à la dose d'inoculum. Lindemann et al (1984) relient l'importance de la maladie à la moyenne de la population pathogène sur chaque feuille de haricot. Rouse et al (1985), qui ont proposé un modèle mathématique de prévision de la maladie en fonction de la population épiphyte à un temps donné, prennent comme seuil critique un niveau de $1 \times 10^{4} \mathrm{~s} \mathrm{pv}$ syringae/g de matière fraîche pour le haricot. Shane et Baumer (1987) l'estiment de $5 \times 10^{5}$ à $1 \times 10^{6} P s$ pv syringae $/ \mathrm{cm}^{2}$ pour le blé. Cette phase épiphyte est donc un élément essentiel dans le cycle biologique des Pseudomonas, l'intensité des dégâts peut être liée à l'importance de cet inoculum.

Lindow et al (1982b) ont constaté qu'il y avait une relation entre le nombre de cellules de $P S$ pv syringae présentes à la surface des organes aériens du maïs et l'intensité des dégâts de gel. Sur vigne, Luisetti et al (1991) ont montré également que les dégâts dus au gel étaient plus intenses lorsque le nombre de $P s$ pv syringae augmentait.

La qualité de l'inoculum bactérien est également un élément important pour la réussite de l'infection. À partir de souches de $P s$ pv morsprunorum isolées sur cerisier et sur prunier, Crosse et Garrett (1970) ont inoculé séparément et en mélange les souches sur chacune des espèces ; ils ont constaté que les souches ne produisaient des dégâts que sur l'espèce hôte d'origine. Ercolani et al (1974) ont également montré que des souches de $P s$ pv syringae isolées du haricot produisent des symptômes typiques du «brown spot disease" alors que des souches isolées d'autres plantes causent des nécroses "mouchetées». À partir d'une collection de souches de $P s p v$ syringae isolées de la microflore de cerisier, Klement et Rozsnyay (1991) constatent qu'elles ne sont pas pathogènes ou pathogènes faibles sur abricotier. En revanche, Cottin (1989) n'a observé aucune différence de faciès au niveau des symptômes obtenus sur différentes plantes, après inoculation par des souches provenant d'un hôte hétérologue. De même, Seemüller et Arnold (1978), Latorre et Jones (1979b), Gross et al (1984a), Endert et Ritchie (1984), Baca et Moore (1987), Malvick et Moore (1988) et Gaignard (1992) ont mis en évidence qu'une souche pathogène d'un hôte était potentiellement pathogène sur d'autres plantes. Hirano et al (1988) ont montré l'existence de sous-populations pathogènes et non pathogènes à l'intérieur de l'espèce $P$ syringae. En fonction de la répartition de celles-ci, il y a apparition ou non de symptômes. Le concept avancé par Latorre et Jones (1979a), selon lequel $P$ syringae est une espèce regroupant des souches pathogènes et des souches non pathogènes, est repris en 1990 par Hirano et Upper. Comme nous l'avons indiqué précédemment, ce point de vue est différent de celui de Klement (1963), repris par Lelliott et al (1966) lors de la mise au point de la clé de détermination des Pseudomonas fluorescents, qui estimait que l'espèce $P$ syringae était composée exclusivement de souches pathogènes. Pour Baca et Moore (1987), P s pv syringae apparaît être un pathogène faible ou facultatif, montrant que $50 \%$ des souches isolées sur les mauvaises herbes en pépinières ne sont pas pathogènes. La conclusion est la même pour Gross et al (1984a), qui ont constaté que seulement $50 \%$ des souches isolées sur arbres fruitiers sont pathogènes sur poire immature et cerise et pour Malvick et Moore (1988) qui ont montré que seulement $15 \%$ des souches isolées sur poirier étaient pathogènes sur semis. Sur feuilles de poirier détachées, Yessad et al (1992) n'ont pas obtenu de symptômes avec toutes les souches de $P s$ pv syringae inoculées par blessure. Les populations de $P s$ pv syringae isolées de laurier palme seraient constituées de sous-populations ayant un spectre d'hôte et un degré d'agressivité variables (Cottin, 1989). Les souches de l'espèce $P$ syringae isolées à partir de l'eau de pluie par Constantinidou et al (1990) sont, pour la plupart, non pathogènes sur haricot et sur soja mais elles sont, en majorité, glaçogènes.

Sur vigne, Luisetti et Gaignard (1986) ont dénombré des populations importantes de $P s \mathrm{pv}$ syringae dans les bourgeons et à la surface des jeunes feuilles, ils n'ont cependant jamais observé de symptômes d'origine bactérienne en vignoble, ce qui semble indiquer que cette bactérie peut survivre sur une plante sans passer par une phase parasitaire. $P S$ pv syringae a été isolé de nécroses de vigne (Panagopoulos, 1969; Prunier et al, 1970b) en mélange avec Xanthomonas ampelina (aujourd'hui Xylophilus ampelinus), mais ces auteurs considèrent son action comme secondaire. $P s \mathrm{pv}$ syringae n'a d'ailleurs été signalé pathogène en vignoble qu'à 2 reprises (i) à partir d'altérations sur pousses et sur feuilles de vigne en Argentine (Klingner et al, 1976); et (ii) à partir de symptômes au niveau de l'écorce et du bois, en Sardaigne (Cucusi et al, 1986). Enfin, Luisetti (données non publiées) a obtenu sur plantule de vigne inoculée avec plusieurs souches de la microflore épiphyte (bour- 
geons), mais dans un seul cas, en condition d'humidité saturante, des dégâts de type bactérien. $P s$ p syringae, germe essentiellement épiphyte et glaçogène sur la vigne, est potentiellement pathogène sur cette plante mais les dégâts bactériens au vignoble sont rares ou peu perceptibles.

\section{Voies d'infection et symptomatologie}

À la différence de nombreux champignons phytopathogènes, les bactéries ne possèdent pas d'organes différenciés leur permettant de pénétrer mécaniquement dans les tissus. La pénétration peut s'effectuer :

- par voie d'entrée naturelle (stomates, trichomes cassés) (Crosse, 1966; Hattingh et al, 1989);

- à la faveur d'une lésion naturelle (plaie pétiolaire ou pédonculaire, base ouverte des trichomes, petites fissures microscopiques dans les dépressions de la couche cuticulaire) (Crosse, 1956; Vigouroux, 1970; Luisetti et al, 1984; Luisetti et Gaignard, 1987b; Mansvelt et Hattingh, 1987a; Luisetti et al, 1992);

- au travers d'une blessure (taille, pluie, grêle, gelée, insectes) (Panagopoulos et Crosse, 1964; Vigouroux, 1970; Luisetti, 1978; Luisetti et al, 1984; Samson et al, 1988; Luisetti et Gaignard, 1989a; Gaignard, 1992; Luisetti et al, 1992);

- par un phénomène consécutif à une fusion de cristaux de glace dans les tissus (Süle et Seemüller, 1987). Les bactéries colonisent alors les espaces intercellulaires du parenchyme des cellules des feuilles et des tiges. Lorsque la pénétration intervient durant les périodes de sensibilité des tissus, la bactérie se multiplie intensément et des dégâts bactériens apparaissent (nécroses sur feuilles, sur pousses, chancres sur charpentières et sur troncs). La plante peut également dépérir partiellement ou complètement: c'est le cas du pêcher avec $P S$ pv persicae (Vigouroux, 1970; Luisetti et al, 1984; Luisetti et al, 1992).

Cameron (1962) a constaté que $P$ syringae pénétrait par les bourgeons de cerisier en Orégon. Luisetti et al (1984) ont vérifié que $P s \mathrm{pv}$ persicae s'installait dans les bourgeons de pêcher dès leur formation et s'y maintenait en hiver. II en est de même sur kiwi avec $P s$ pv syringae (Luisetti et Gaignard, 1987b). Ceci peut entraîner la nécrose, durant l'hiver, d'un nombre important de bourgeons qui ne se développeront pas.

En revanche, en période de non sensibilité de l'arbre, l'inoculation conduit, certes, à une multiplication des bactéries dans les tissus durant 2 ou 3 semaines mais ne permet qu'un développement limité des dégâts, qui s'apparentent plus à une "réaction d'hypersensibilité" (Crosse, 1966; Shane et Baumer, 1987). En période de non sensibilité sur pêcher, Prunier et al (1973), après inoculation de $P s$ pv persicae, observent des réactions plus ou moins atypiques, qui pourraient aussi correspondre à une réaction d'hypersensibilité. La sensibilité propre de chaque variété joue un rôle dans la réponse de l'hôte (Cameron, 1962). Gardan et al (1971) ont vérifié ce phénomène sur une gamme de variétés de pêcher; dans le cas d'attaques limitées, l'arbre peut résister à l'attaque et l'on voit des chancres ouverts se cicatriser; ces chancres peuvent reprendre ultérieurement de l'activité et constituer des voies d'entrée pour d'autres parasites.

\section{Facteurs abiotiques influençant l'infection}

Les facteurs extérieurs, sol, climat, eau et éléments minéraux conditionnent également l'infection. Certains facteurs du sol, et plus largement du système cultural, ont une influence prédisposante sur les pêchers vis-à-vis de $P s$ pv persicae (Vigouroux et al, 1987). L'aire d'extension de cette maladie est d'ailleurs limitée aux sols acides de la vallée du Rhône (Vigouroux et Huguet, 1980). Le rôle du calcium paraît prépondérant et plusieurs modes d'action sont envisageables et, en particulier, il pourrait consolider les parois cellulaires (Ginzburg, 1961; Simon, 1978; Clarkson et Hanson, 1980), réduire les microlésions liées au gel et donc les possibilités de pénétration de la bactérie dans l'hôte (Durand et al, 1967) et freiner la désorganisation des parois liée à l'activité bactérienne (Davies et English, 1969; Mc Guire et Kelman, 1986). Backman et de Vay (1971) ont montré que la syringomycine agit sur l'intégrité de la membrane cellulaire et que les ions $\mathrm{Ca}^{2+}$ ont un important pouvoir d'inhibition de cette toxine. Luisetti et Gaignard (1984b) ont montré une action identique du calcium vis-à-vis de la toxine produite par $P s \mathrm{pv}$ persicae. Le potassium a un rôle important dans le métabolisme de l'eau en général, y compris en hiver. II pourrait donc influencer le 
comportement des plantes au froid, ce dernier facteur étant un élément essentiel de prédisposition du pêcher au dépérissement bactérien (Vigouroux, 1974).

Les températures négatives interviennent dans le développement des maladies bactériennes des plantes soit en créant les conditions favorables à la pénétration bactérienne, soit en augmentant la sensibilité des tissus à ces microrganismes. En Hongrie et en Yougoslavie, les dégâts les plus sévères de dépérissement bactérien de l'abricotier dû à $P s$ pv syringae sont observés après des hivers très rigoureux (Klement et al, 1972). Les cycles de gel et de dégel, intervenant en hiver, en provoquant un afflux d'eau dans les espaces intercellulaires des tissus parenchymenteux (water soaking), favoriseraient la pénétration et le développement de l'infection du pêcher par $P s$ pv persicae (Vigouroux, 1974; $1979 ; 1989 ; 1991$ ) et par $P s$ pv syringae (Weaver, 1978) et de l'abricotier par $P$ s pv syringae (Klement et al, 1974; Vigouroux, 1989). Whitesides et Spotts (1991) constatent sur poirier que gel, humidité et stade phénologique sont des éléments déterminants dans l'infection due à $P s \mathrm{pv}$ syringae. Klement et Rozsnyay (1991) ont constaté que l'activité glaçogène des souches n'était pas un facteur de virulence de $P s$ pv syringae sur abricotier en hiver.

Dès 1964, Panagopoulos et Crosse constataient que les gelées de printemps prédisposaient le poirier au dessèchement bactérien dû à $P s$ pv syringae. Sur poirier aussi, Durand et al (1967) ont démontré qu'au printemps les dégâts bactériens étaient toujours consécutifs à un coup de gel. En conditions expérimentales, Luisetti et Gaignard (1989a) ont confirmé, sur pêcher, forsythia et kiwi conduits en conteneurs, que l'activité glaçogène de certaines souches était un des éléments intervenant dans le processus infectieux de $P s$ pv syringae glaçogène. Sur vitroplant de kiwi, Gaignard (1992) a vérifié ce phénomène avec les mêmes bactéries. Luisetti (1978), analysant le problème des bactérioses consécutives au gel de printemps, reprend le concept avancé par Genevès (1955), portant sur les effets d'un gel limité; l'eau extraite des cellules entraîne alors des substances nutritives favorables aux agents pathogènes et à leur multiplication; la congélation provoque des décollements d'épiderme et des microlésions permettant la pénétration des microrganismes. Gross et al (1984a) ont constaté également que le pouvoir glaçogène pouvait faciliter l'infection et la multiplication de $P$ $s$ pv syringae.

\section{Éléments intervenant dans le pouvoir pathogène}

Les plantes peuvent adopter un mécanisme de reconnaissance similaire à celui qui se passe entre pollen et stigmate dans les interactions entre cellule végétale et microrganismes (Sequeira, 1978). Les plantes rejettent la majorité des microrganismes pathogènes avec lesquels elles sont en contact. Quelques pathogènes contournent cette difficulté : on assiste alors à des coévolutions hôte/parasite.

Les mécanismes biochimiques en présence sont nombreux, difficiles à expliquer et loin d'être tous élucidés. Parmi les éléments intervenant lors d'une interaction, on peut citer les lectines produites par les plantes, les exopolysaccharides (EPS) synthétisés par les bactéries (Sequeira, 1985). Dans les espaces intercellulaires les EPS auraient plusieurs rôles dans le développement infectieux : imbibition d'eau (water soaking) et concentration d'éléments nutritifs (Billing, 1987) mais aussi protection des cellules bactérienne contre l'agglutination. Le EPS (exopolysaccharide) et le LPS (lypopolysaccharide) des bactéries à Gram négatif pourraient être impliqués dans les phénomènes de reconnaissance.

Les bactéries phytopathogènes produisent des enzymes extracellulaires capables de dégrader les composants des parois des cellules végétales. On trouve notamment des pectinases: une pectate lyase a été mise en évidence chez $P$ viridiflava par Liao et Wells (1987) et des cellulases. Des souches de $P s$ pv savastanoi induisant la tuberculose de l'olivier et des tumeurs sur le laurier rose produisent in vitro de l'acide indole acétique et des cytokinines (Surico et al, 1975).

La production de toxine apparaît être également un élément important du pouvoir pathogène. II semble que la syringomycine produite par $P$ s pv syringae perturbe les fonctions physiologiques localisées au sein des membranes plasmiques des cellules hôtes (Gross et Cody, 1985; Zhang et Takemoto, 1987). Xu et Gross (1988a) ont précisé à partir d'un travail réalisé avec des mutants de $P s$ pv syringae que la syringomycine contribuait significativement au niveau de la virulence de la bactérie. Luisetti (1983) a constaté que l'agressivité des souches de $P s$ pv persicae était corrélée avec leur aptitude à produire de la toxine.

Des exemples de résistance acquise après une agression bactérienne sur concombre et sur 
tabac et s'apparentant à une réaction d'immunité sont cités par Sequeira (1983). La réaction d'hypersensibilité suivant l'introduction de bactéries (et de virus) provoque chez le tabac l'apparition d'une résistance à une seconde infection; le collapsus dû à l'injection dans les feuilles de bactéries phytopathogènes ( $P$ syringae) peut être partiellement ou totalement supprimé par une inoculation préalable avec le virus de la mosaïque du tabac et inversement (Ahl et al, 1981). L'induction de cette résistance s'accompagne de l'apparition de nouvelles protéines solubles (protéines $b$, aujourd'hui appelées protéines PR pour pathogenesis related) produites par la plante.

L'existence de races chez $P s$ pv syringae a été mise en évidence (Garrett, 1978) : $83 \%$ des nouveaux cultivars de cerisier testés sont résistants à la première race de $P s \mathrm{pv}$ morsprunorum alors que seulement $32 \%$ le sont à la seconde race isolée plus récemment. Ceci montre la difficulté que l'on peut rencontrer dans le cadre de l'amélioration variétale. Pour la première fois en 1987 un gène d'avirulence avr porté par les souches d'une race de $P s$ pv glycinea, responsable de la graisse du soja, a été isolé par Staskawicz et al.

L'apparition des symptômes de la maladie ou l'induction de la résistance, lors de l'infection d'une plante par un microrganisme pathogène, résulte d'une série d'événements biochimiques successifs (ou signaux biochimiques) qui dépendent de l'interaction entre des fonctions codées par le génome du parasite et par celui de la plante. La vie épiphyte est-elle réglée par les mêmes mécanismes ? La préparation de mutants affectés dans le pouvoir pathogène après mutagenèse aléatoire, et l'identification des fonctions biochimiques altérées chez ces mutants, est une des voies permettant d'identifier les gènes impliqués dans les interactions plantes/ bactéries phytopathogènes.

L'inoculation à une gamme de plantes de ces différents mutants, préparés à partir de souches provenant de différents hôtes, permettra peutêtre d'élucider la question de l'ubiquité ou de la spécificité/préférence d'hôte dans le pouvoir pathogène du pathovar syringae et de préciser ses principales composantes. On pourrait aussi analyser le comportement épiphyte de ces mutants et vérifier la présence de médiateurs chimiques qui pourraient être induits par la présence de la bactérie à la surface de la feuille, comme le suspectent Hirano et Upper (1990). L'existence d'une relation entre le pouvoir pathogène des souches et leur aptitude à coloniser la phyllosphère, comme le suggèrent Yessad et al (1991), pourrait être également vérifiée. Ces travaux permettraient peut-être alors de préciser la différence entre bactérie «résidente» et bactérie «fortuite», différence constatée par Leben dès 1965.

\section{Méthodes de lutte contre les $\mathrm{P}$ syringae}

Dans la mesure où la population épiphyte constitue le réservoir essentiel d'inoculum, l'objectif d'une lutte efficace doit être de réduire le niveau de ces populations au-dessous d'un seuil de nuisibilité. II s'agit toujours d'une lutte préventive et raisonnée qui conduit à intervenir lorsque la bactérie est accessible et durant ses périodes de multiplication. Différentes voies de lutte, chimique et biologique, sont à exploiter ainsi que des voies plus indirectes, comme les mesures prophylactiques et l'ajustement des itinéraires techniques.

La compréhension de la phase épiphyte, des interactions entre la plante et la bactérie, du rôle des médiateurs chimiques et de l'influence de l'environnement dans la dynamique des bactéries devrait permettre demain d'innover efficacement en matière de lutte.

À plus long terme, avec le développement du génie génétique, on peut espérer déboucher sur la création de variétés résistantes aux Pseudomonas dans la mesure où l'on sera capable d'identifier et d'isoler des gènes de résistance.

\section{Lutte chimique}

Deux types de produits présentant une activité antibactérienne sont actuellement utilisés dans la lutte chimique préventive : il s'agit de sels de cuivre (Cameron, 1962; Ercolani, 1967; Matthee et Erskine, 1971; Prunier et al, 1985) et des antibiotiques. En 1974, sur pêcher, Prunier et al ont présenté les premiers résultats rapportant l'efficacité de ces produits pour abaisser les populations épiphytes de $P s$ pv persicae au cours de l'automne. Luisetti et al (1984) ont proposé également, compte tenu de l'installation de $P s \mathrm{pv}$ persicae dans les bourgeons dès leur formation, de lutter contre cette bactérie au printemps. Mais seule l'utilisation d'antibiotique est possible à cette période du fait de la phytotoxicité du cuivre. Lindow (1983b) et Lindow et Connel (1984), respectivement sur le poirier et sur l'amandier, ont 
obtenu des résultats similaires contre $P s p v s y$ ringae, par des traitements de printemps. Conlin et Mc Carter (1983) obtiennent également une réduction des populations de $P s$ pv tomato sur tomate en plein champ après l'application de streptomycine et d'hydroxyde de cuivre. Menkissoglu et Lindow (1991a, b) notent que les formes de cuivre solubles ont une efficacité limitée alors que les bactéries sont sensibles aux formes ioniques.

Le plus grand danger potentiel des antibiotiques concerne leur action sur la composition de la microflore bactérienne présente à la surface des plantes, et plus particulièrement la sélection de bactéries résistantes. Lorsque cette résistance est liée à des plasmides, le risque de transfert de bactérie à bactérie par simple conjugaison existe chez les Pseudomonas (Chabbert, 1973). Sur kiwi, Goto (1991) constate l'apparition de souches d'un pathovar de $P$ syringae résistantes à la streptomycine et au cuivre ; cette résistance à la streptomycine s'est développée depuis 1987 , annee d'autorisation de l'utilisation de cet antibiotique au Japon ; ces résistances seraient associées à des plasmides. Sobiczewski et al (1991) notent que l'usage intensif de streptomycine sur pommier au Michigan a entraîné l'apparition de germes résistants à cet antibiotique, autant chez l'espèce $P$ syringae que chez les espèces saprophytes.

L'emploi des antibiotiques en France n'est autorisé que dans le cas des maladies graves (Coléno et al, 1982). Un seul antibiotique, la fluméquine (famille des quinolones), pour laquelle on n'a pas mis en évidence de résistance plasmidique, est actuellement autorisé pour lutter contre le feu bactérien des rosacées fruitières et ornementales ( $E$ amylovora); il est aussi utilisé dans la lutte contre le desséchement bactérien du poirier ( $P s$ pv syringae) et contre le dépérissement bactérien du pêcher ( $P s$ pv persicae) (Brisset et al, 1991; Luisetti et Gaignard, 1991). Un autre antibiotique, la kasugamycine, a fait également l'objet d'essais vis-à-vis de plusieurs pathovars de $P$ syringae; ce produit présente une nette efficacité contre les Pseudomonas mais il n'est pas autorisé en France actuellement (Luisetti et al, 1990). Hiramatsu et al (1990) ont aussi observé la bonne efficacité de cet antibiotique vis-à-vis des bactéries phytopathogènes dont des Pseudomonas sur riz, haricot et concombre ; Nemeth et al (1990) ont obtenu de bons résultats vis-à-vis de $P s$ pv lachrymans sur concombre et de $P s$ pv tomato sur tomate. Le mélange kasugamycine et cuivre semble d'ailleurs plus efficace que les 2 produits appliqués séparément (Hiramatsu et al, 1990).

Trois formulations cupriques (sulfate de cuivre, hydroxyde de cuivre et chelate de cuivre) sont homologuées en France pour la lutte contre les maladies bactériennes des plantes dues aux Pseudomonas (Luisetti et al, 1992; Gaignard et Luisetti, 1992b). La phytotoxicité des sels de cuivre est un problème sérieux qui limite leur utilisation ; l'amélioration des formulations permettrait leur plus large utilisation (Coléno et al, 1982). La résistance aux métaux lourds, au cuivre en particulier, est également à considérer (Andersen et al, 1991). Sundin et al (1989) ont isolé sur cerisier des souches de $P s \mathrm{pv}$ syringae résistantes au cuivre ; cette résistance serait d'origine plasmidique. En revanche, Lindow et Rogers (1991), qui isolent également sur arbres fruitiers des souches de $P s$ pv syringae résistantes au cuivre, ont montré que cette résistance était portée par le chromosome bactérien. Gaignard et Luisetti (1992a) proposent d'utiliser le vitroplant pour cribler l'efficacité de formulations et de molécules nouvelles vis-à-vis des Pseudomonas en phase épiphyte ; ce type d'étude permettrait de travailler sur un nombre élevé de produits sans dispersion dans la nature.

\section{Lutte biologique}

Cette voie de lutte a connu un certain développement après la mise en évidence du pouvoir glaçogène de $P s \mathrm{pv}$ syringae. Une démarche consiste à sélectionner d'abord des souches qui présentent in vitro une activité antagoniste vis-àvis de la bactérie qu'on souhaite éliminer, puis à obtenir une bonne installation sur la plante des souches sélectionnées et une expression in situ de l'effet antagoniste (Andrews, 1985). Leben (1985) rappelle que les antagonistes bactériens sur jeune plante et sur plante plus âgée peuvent être différents et Lindow (1988a) note également que l'activité antagoniste des souches sélectionnées in vitro ne s'exprime pas toujours sur la plante. Ceci montre quelques-unes des difficultés de mise en œuvre d'une lutte biologique.

Des résultats positifs ont cependant été obtenus. Sobiczewski (1987) a isolé 4 souches (Pseudomonas non fluorescents, $E$ carotovora, $E$ herbicola et une Entérobactérie) capables de protéger les fruits verts de cerisiers contre $P S$ pv syringae. Luisetti et Gaignard (données non 
publiées) ont limité la multiplication de $P s \mathrm{pv} s y$ ringae sur vigne conduite en conditions contrôlées avec une souche d'E herbicola. Lindow (1982) a réduit de 10 à 500 fois la population de $P$ syringae glaçogène par l'apport de bactéries antagonistes. Cody et al (1987), qui préfèrent sélectionner les souches d'abord sur leur aptitude à la colonisation du phylloplan, ont réussi à abaisser de 10 à 100 fois les populations de $P S$ pv syringae sur poirier avec des souches de $P$ fluorescens et de $P$ putida antagonistes ce qui ne modifie cependant pas le seuil de gélivité de la plante. Après installation sur maïs d'une levure (Candida sp) antagoniste de $P s$ pv syringae, Kim et al (1989) ont obtenu une réduction de l'intensité des dégâts de gel.

Morris et Rouse (1985) proposent d'associer un deuxième élément dans la lutte mettant en œuvre une bactérie antagoniste. II s'agit d'une lutte dans laquelle serait pris en compte le rôle des éléments nutritifs qui régulent la vie épiphyte. II serait nécessaire de mener des études préliminaires sur les profils physiologiques des bactéries concernées pour identifier les éléments utilisés seulement par la bactérie antagoniste et de les apporter lors de l'application bactérienne sur les plantes.

Une autre stratégie de lutte biologique a été proposée par Lindow (1988a, b) et Lindow et Panopoulos (1991); elle consiste à installer sur les plantes, très tôt au printemps, un mutant non glaçogène de $P s$ pv syringae, construit par délétion du gène ice. Le but est d'obtenir une colonisation de la plante par une bactérie ayant les mêmes besoins nutritionnels que la souche sauvage glaçogène. C'est d'ailleurs la première expérience d'utilisation d'un microrganisme génétiquement modifié dans la lutte contre les maladies bactériennes des plantes. Leurs résultats montrent une limitation des populations de $P s \mathrm{pv}$ syringae naturelles glaçogènes à un niveau bas et de faibles dégâts de gel. Lindow et Panopoulos (1991) ont vérifié que le mutant non glaçogène ne se dispersait pas au delà de $30 \mathrm{~m}$ de son point d'application et n'était plus mis en évidence, 30 jours après son application.

\section{Mesures prophylactiques et choix des itinéraires techniques}

Sur le modèle $P s$ pv persicae/pêcher, un certain nombre de conseils sont proposés par Luisetti et al (1992), permettant de limiter la dissémination de la bactérie et l'explosion de la maladie. Ils peuvent être étendus pour les arbres fruitiers à l'ensemble des maladies bactériennes dues aux Pseudomonas. II s'agit d'installer des variétés peu sensibles à la bactérie et des plants de pêcher indemnes de bactéries, provenant de pépinières contrôlées, d'adapter le porte-greffe au sol, dans des parcelles irrigables, d'éviter les plantations dans des terrains froids, trop caillouteux ou sablo-caillouteux acides, dans des sols maigres, de tailler les arbres lorsque la sensibilité des tissus est moindre, de désinfecter le sécateur entre chaque arbre de surveiller en permanence les arbres et d'éliminer toute partie ou arbre malade.

\section{Conclusion}

L'espèce $P$ syringae montre une large diversité tant au niveau de son profil physiologique que de son pouvoir pathogène. II apparaît indispensable que soit reprécisée rapidement la classification en pathovars qui, à l'heure actuelle, ne satisfait plus les phytobactériologistes. L'utilisation des techniques de génétique et de biologie moléculaire devrait permettre une définition plus rigoureuse de l'espèce et des pathovars actuellement décrits. La diversité de cette espèce bactérienne en fait également un modèle pour mener une étude d'évolution.

Le cas du pathovar syringae est particulièrement intéressant puisqu'il exhibe une diversité aussi large que l'espèce elle-même ; cette variabilité pourrait cacher l'existence d'entités plus homogènes qui devraient alors être individualisées comme de nouveaux pathovars, voire, pourquoi pas, comme de nouvelles espèces. Une analyse taxonomique du pathovar, mettant en œuvre hybridation et sondes, permettrait de clarifier une situation encore très confuse.

La notion de spécificité d'hôtes qui s'applique très bien à la plupart des pathovars de $P$ syringae n'a, actuellement, aucun sens pour le pathovar syringae. Il est urgent de savoir si une spécificité d'hôtes peut être attachée aux souches composant ce pathovar. Puisque des résultats récents semblent indiquer l'existence d'une certaine spécificité qui, selon certains auteurs, pourrait correspondre plutôt à une préférence d'hôtes, il est nécessaire de mettre au point, rapidement, une méthodologie permettant de révéler le pouvoir pathogène de souches qui, rappelons le, provoquent systématiquement une réaction nécrotique de type hypersensibilité, sur tout hôte 
hétérologue. La caractérisation des situations compatibles et incompatibles par la cinétique des fuites d'électrolytes, comparée aux résultats d'inoculations sur plante, pourrait permettre de distinguer un hôte homologue d'un hôte hétérologue pour chacune des souches du pathovar syringae.

Au plan de la connaissance du processus infectieux, les travaux sur l'activité glaçogène des Pseudomonas permettent aujourd'hui de mieux comprendre la réalisation de la phase initiale de pénétration et de prendre en compte le rôle de l'environnement, climatique en particulier, dans la réussite de l'infection et le développement des maladies à $P$ syringae.

L'aptitude épiphyte, caractéristique commune à tous les pathovars de $P$ syringae, reste, malgré les connaissances acquises récemment, encore mal connue. Elle revêt une importance primordiale au niveau du déroulement du cycle biologique de la bactérie puisqu'elle assure la conservation et la pérennisation de l'inoculum. C'est à ce niveau que l'on devrait pouvoir espérer innover en matière de lutte ; malheureusement les connaissances de base manquent encore. L'approche génétique de cette propriété, bien que se heurtant à quelques difficultés d'ordre méthodologique, devrait permettre de révéler la nature des liens entre une bactérie épiphyte et son hôte et confirmer, peut-être, l'existence d'une relation étroite entre spécificité parasitaire et spécificité épiphyte, d'où probablement de nouvelles stratégies de lutte.

Sans aller aussi loin dans la compréhension des mécanismes de l'interaction, on peut aussi penser que parvenir à modéliser la dynamique des populations épiphytes, du niveau desquelles dépend le succès d'une infection, en fonction des paramètres climatiques, devrait permettre de définir un système de prévision de maladie, base indispensable à toute lutte raisonnée, certains pathovars, homogènes dans leur composition, constituant des supports adéquats à ce type d'étude.

La mise en commun des connaissances acquises sur $P$ syringae et sa biologie a déjà permis d'élaborer une stratégie de lutte ayant une certaine efficacité. L'approfondissement de ces connaissances au niveau de la génétique du pathogène et de la biologie moléculaire de l'interaction, qu'elle se situe au niveau parasitaire ou épiphyte, doit favoriser dans le futur l'émergence d'une lutte plus performante.

\section{RÉFÉRENCES}

Ahl P, Benjama A, Samson R, Gianinazzi S (1981) Induction chez le tabac par Pseudomonas syringae de nouvelles protéines (protéines "b") associées au développement d'une résistance non spécifique à une deuxième infection. Phytopathol $Z$ 102, 201212

Andersen GL, Menkissoglou O, Lindow SE (1991) Occurrence of properties of copper-tolerant strains of Pseudomonas syringae isolated from fruit trees in California. Phytopathology 81, 648-656

Anderson JA (1988) Ice-nucleation of seedlings of six tomato cultivars. Hortscience 23, 1044-1045

Anderson JA, Ashworth EN (1985) Ice nucleation in tomato plants. J Am Soc Hortic Sci 110, 291-296

Anderson JA, Buchanan DW, Ingram DL (1981) The role of Pseudomonas syringae, an ice nucleation active bacterium, in frost damage of tender annual plants. Proc Fla State Hort Soc 94, 72-74

Anderson JA, Buchanan DW, Stall RE, Hall CB (1982) Frost injury of tender plants increased by Pseudomonas syringae Van Hall. J Soc Hortic Sci 107, 123-125

Anderson JA, Ashworth EN, Davis GA (1987) Nonbacterial ice nucleation in Peach shoots. $J$ Amer Soc Hortic Sci 112, 215-218

Andrews JH (1985) Strategies for selecting antagonistic microorganisms from the phylloplane. In: Biological control on the phylloplane (CE Windels, SE Lindow, eds) Am Phytopathol Soc, St Paul 31-44

Andrews PK, Proebsting EL, Gross DC (1983) Differential thermal analysis and freezing injury of deacclimating peach and sweet cherry reproductive organs. J Amer Soc Hortic Sci 108, 755-759

Arlat $M$, Boucher $C$ (1989) Les gènes hrp: des gènes clés contrôlant le pouvoir pathogène des bactéries. C R Acad Agric Fr, 75, 6, 73-77

Arny DC, Lindow SE, Upper GD (1976) Frost sensitivity of Zea mays increased by application of Pseudomonas syringae. Nature 262, 282-284

Arsenijevic (1973) Further investigations on Pseudomonas syringae Van Hall as pathogen of apricot in Yugoslavia. Proc working group Pseudomonas syringae 60-66, Angers, avril 1973

Arsenijevic (1986) Pathogenic and serologic characteristics of Pseudomonas syringae pv syringae Van Hall originating from wheat. Zastita Pilja 37, 213224

Ashworth EN, David GA (1984) Ice nucleation within peach trees. J Am Soc Hortic Sci 109, 198-201

Ashworth EN, Davis GA, Anderson JA (1985a) Factors affecting ice nucleation in plant tissues. Plant Physiol 79, 1033-1037

Ashworth EN, Anderson JA, Davis GA, Lightner GW (1985b) Ice formation in Prunus persica under field conditions. J Am Soc Hortic Sci 110, 3, 322-324 
Baca S, Moore LW (1987) Variations in Pseudomonas syringae isolated from grass species occuring in woody plant nurseries in the pacific northwest. Plant Dis 71, 724-726

Baca S, Canfield ML, Moore LW (1987) Variability in ice nucleation strains of Pseudomonas syringae isolated from disease woody plants in Pacific northwest nurseries. Plant Dis 71, 412-415

Backman PA, de Vay JE (1971) Studies on the mode of action and biogenesis of phytotoxin syringomycin. Physiol Plant Pathol 1, 215-233

Banapor A, Zarii Z, Amani G (1990) Isolation of Pseudomonas syringae from sweet cherry trees in Tehran. Iran J Plant Pathol 26, 25-27

Barker BTP, Grove O (1914) A bacterial disease of fruit blossom. Ann Appl Biol 1, 85-97

Barthakur N, Maybank J (1963) Anomalous behaviour of some amino-acids as ice nucleators. Nature 200, 866-868

Barzic MR (1985) Les toxines des bactéries phytopathogènes. Bull Inst Pasteur 83, 245-287

Bashan Y, Sharon E, Okon J, Henis Y (1981) Scanning electron and light microscopy of infection and symptom development in tomato leaves infected with Pseudomonas tomato. Physiol Plant Pathol $19,139-144$

Bazzi C, Calzolari A (1983) Bacterial blister spot of "Mutsu" apples in Italy. Phytopathol Mediterr 22, 19-21

Bergey's Manual of Determinative Bacteriology (1974) (Buchanan RE, Gibbons NE, eds) ed 8, Williams \& Wilkins, Baltimore $1246 \mathrm{p}$

Bergey's Manula of Systematic Bacteriology (1984) (Krieg NR, Holt JG, eds) tome 1, Williams \& Wilkins, Baltimore $964 \mathrm{p}$

Billing $E$ (1987) Bacteria as plants pathogens. Van Nostrand Reinhold (UK) Co Ltd (ed), 79 p

Billing E, Garrett CME (1983) Phages in the identification of plant pathogenic bacteria. In: Microbial classification and identification (M Goodfellow \& RG Board, eds) Acad Press, Toronto, 319-338

Blakeman JP (1985) Ecological succession of leaf surface microorganisms in relation to biological control. In: Biological control of the phylloplane (CE Windels, SE Lindow, eds) Amer Phytopathol Soc, St Paul 6-30

Bordjiba O, Prunier JP (1991) Establishment of an epiphytic phase by three species of Pseudomonas on apricot trees. Acta Hortic 293, 487-494

Boucher CA, Van Gijsegem F, Barberis PA, Arlat M, Zischek C (1987) Pseudomonas solanacearum genes controlling both pathogenicity on tomato and hypersensitivity on tobacco are clustered. J Bacteriol 169, 5626-5632

Bradbury JF (1986) Guide to Plant Pathogenic Bacteria. $\mathrm{CAB}$ International Mycological Institute (ed), Slough $332 p$
Brisset MN, Paulin JP (1991) Relationships between electrolyte leakage from Pyrus communis and virulence of Enwinia amylovora. Physiol Mol Plant Pathol 39, 443-453

Brisset MN, Luisetti J, Gaignard JL (1991) Firestop: a chemical against bacterial diseases of fruit trees recently available in Europe. agronomie 11, 93-99

Bryan MK (1928) Lilac blight in the United States. $J$ Agric Res 36, 225-235

Buchanan RE (1917) Studies on the nomenclature and classification of the bacteria. 3 . The families of Eubacteriales. J Bacterio/ 2, 347-350

Burke MJ, Gusta LA, Quamme HA, Weiser CJ, Li PH (1976) Freezing and injury to plants. Annu Rev Plant Physiol 27, 507-528

Burr TJ, Katz BH (1984) Overwintering and distribution pattern of Pseudomonas syringae pv papulans and pv syringae in apple buds. Plant Dis 68, 383-385

Cameron HR (1962) Mode of infection of sweet cherry by Pseudomonas syringae. Phytopathology 52, 917-921

Cameron HR (1970) Pseudomonas content of cherry trees. Phytopathology 60, 1343-1346

Cancino L, Latorre B, Larach W (1974) Pear blast in Chili. Plant Dis Rept 58, 568-570

Canfield ML, Baca S, Moore LW (1986) Isolation of Pseudomonas syringae from 40 cultivars of diseased woody plants with tip dieback in Pacific northwest nurseries. Plant Dis 70, 647-650

Carry JW, Lindow SE (1986) The effect of leaf water variables on ice nucleating $P$ seudomonas syringae in beans. Hortscience 21, 1417-1418

Casano FJ, Hung SY, Wells JM (1987) Differentiation of some pathovars of Pseudomonas syringae with monoclonal antibodies. Bulletin OEPP 17, 173-176

Chabbert YA (1973) Données actuelles sur la résistance des bactéries aux antibiotiques. In: Actual Pharmacol, 26e série (Masson, éd) 27-60

Clarkson DT, Hanson JB (1980) The mineral nutrition of higher plants. Annu Rev Plant Physiol 31, 239298

Cochet N, Blanc C, Luquet MP, Bouabdillah D, Clausse D (1991) Production of ice nucleation active bacteria. Proc 7th Int Conf Surface and Colloid Sci, Compiègne, July 1991

Cody YS, Gross DC, Proebsting EL, Spotts RA (1987) Suppression of ice nucleation-active Pseudomonas syringae by antagonistic bacteria in fruit tree orchards and evaluation of frost control. Phytopathology $77,1036-1044$

Coléno A (1973) Contribution à l'étude taxonomique de quelques Pseudomonas phytopathogènes. Thèse doctorat d'État, univ Rennes, $127 \mathrm{pp}$

Coléno A, Gardan L, Luisetti J, Paulin JP (1982) Les antibiotiques et la lutte contre les maladies bactériennes des plantes. In : Les Maladies des plantes $2^{e}$ journées françaises d'études et d'informations, Paris, octobre 1979 (Acta, Paris éd) 355-362 
Conlin KC, Mc Carter SM (1983) Effectiveness of selected chemicals in inhibition Pseudomonas syringae $\mathrm{pv}$ tomato in vitro and in controlling bacterial speck. Plant Dis 67, 639-644

Constantinidou HA, Hirano SS, Baker LS, Upper CD (1990) Atmospheric dispersal of ice nucleation active bacteria: the role of rain. Phytopathology 80 , 934-937

Constantinidou HA, Menkissoglu O, Stergiadou HC (1991) The role of ice nucleation active bacteria in supercooding of citrus tissues. Physiol Plant 81, 548-554

Corotto LV, Wolber PK, Warren GJ (1986) Ice nucleation activity of Pseudomonas syringae: mutagenesis, complementation analysis and identification of a gene product. EMBO J 5, 231-236

Cottin S (1989) La criblure bactérienne du laurier palme due à Pseudomonas syringae pv syringae. Thèse d'univ, univ d'Angers

Crosse JE (1955) Bacterial canker of stone-fruits. 1. Field observations on the avenues of automnal infection of cherry. J Hortic Sci 30, 131-142

Crosse JE (1956) Bacterial canker of stone-fruits. 2. Leaf scar infection of cherry. J Hort Sci 31, 212-24

Crosse JE (1959) Bacterial canker of stone-fruits. 4. Investigation of a method for measuring the inoculum potential of cherry trees. Ann Appl Biol 47, 306-317

Crosse JE (1966) Epidemiological relations of the pseudomonad pathogens of deciduous fruit trees. Annu Rev Phytopathol 4, 291-310

Crosse JE (1971) Interaction between saprophytic and pathogenic bacteria in plant disease. In: Ecology of Leaf Surface Microorganisms (London Acad, ed) 283-290

Crosse JE, Garrett CME (1963) Studies on the bacteriophagy of Pseudomonas morsprunorum, Pseudomonas syringae and related organisms. J Appl Bacteriol 23, 159-177

Crosse JE, Garrett CME (1970) Pathogenicity of Pseudomonas morsprunorum in relation to host specificity. J Gen Bacteriol 62, 315-327

Cucusi M, Garau R, Prota U, Doré M (1986) A bark necrosis of grapevine caused by Pseudomonas syringae V Hall, In Sardinia. J Phytopathol 116, 176-185

Currier TC, Morgan MK (1983) Plasmids of Pseudomonas syringae: no evidence of a role of toxin production in pathogenicity. Can J Microbiol 29, 84-89

Daft GC, Leben C (1972) Bacterial blight of soybeans: epidemiology of blight outbreaks. Phytopathology $62,57-62$

Davis SR, English H (1969) Factors related to the development of bacterial canker in peach. Phytopatho$\log y 59,588-595$

Denny TP (1987) Application of restriction fragment length polymorphis analysis to the systematics of Pseudomonas syringae pathovars. Proc 3rd international working group on Pseudomonas syringae pathovars 18-20. Lisboa, sept 1987
Denny TP (1988) Phenotypic diversity in Pseudomonas syringae pv tomato. J Gen Microbiol 134, 1939-1948

Doidge EM (1917) A bacterial blight of pear blossoms in South Africa. Ann App/ Biol 4, 50-74

Dowler WM, Petersen DH (1967) Transmission of Pseudomonas syringae in peach trees by bud propagation. Plant Dis Reptr 51, 666-668

Dowler WM, Weaver DJ (1975) Isolation and characterization of fluorescent pseudomonads from apparently healthy peach trees. Phytopathology 65, 233-236

Durand R, Luisetti J, Meynier M, Ridé M (1967) Infektion durch Pseudomonas syringae nach leichtem Frost. $X$ Agrar Dreilander Bavendorf

Dye DW (1956) Blast of Pear. Orchardist N Z 29, 5-7

Dye DW, Bradbury JF, Goto M, Hayward AC, Lelliott RA, Schroth MN (1980) International standards for naming pathovars of phytopathogenic bacteria and a list of pathovar names and pathotype strains. Rev Plant Pathol 59, 4, 153-168

Endert E, Ritchie DF (1984) Overwintering and survival of Pseudomonas syringae pv syringae and symptom development in peach trees. Plant Dis $68,468-470$

English H, Davis JR (1960) The source of inoculum for bacterial canker and blast of stone fruit trees. Phytopathology 50, 634

Ercolani GL (1967) Aspetti di Pseudomonas syringae nei fruitteli emiliani. Inf Fitopatol 17, 205-215

Ercolani GL (1969a) Sopravvivenza epitifica di popolazioni di Pseudomonas morsprunorum Wormald da Ciliego e di $P$ Syringae Van Hall da Pero sulla pianta ospite di provenizza e sull'atra pianta. Phytopathol Mediterr 8, 3, 197-206

Ercolani GL (1969b) Sopravvivenza di Pseudomonas Van Hall sul Pero in rapporto all'epoca della contaminazione, in Emilia. Phytopathol Mediterr 8, 3, 207-216

Ercolani GL, Vannella S (1986) Characterisation of the distribution of individual response times in bacterial infection of plants. Ann Appl Biol 108, 275290

Ercolani GL, Hagedorn DJ, Kelman A, Rand RE (1974) Epiphytic survival of Pseudomonas syringae on hairy vetch in relation to epidemiology of bacterial brown spot of bean in Wisconsin. Phytopathology 64, 1330-1339

Fresh RW (1973) Microbiological production of freezing nuclei from decomposing tree leaves. Pep AR 106, Dept Atmos Res, Univ Wyoming, Larami, $15 \mathrm{p}$

Fryda SJ, Otta JD (1978) Epiphytic movement and survival of Pseudomonas syringae on spring wheat. Phytopathology 68, 1064-1067

Gaignard JL (1992) Apport de la culture in vitro dans l'étude de l'interaction de Pseudomonas syringae avec des plantes ligneuses. Mémoire Diplôme Rech Univ Nantes 
Gaignard JL, Luisetti J (1992a) Criblage de molécules chimiques actives contre Pseudomonas syringae pv syringae sur plants de vigne cultivés in vitro et in situ. agronomie 12, 401-409

Gaignard JL, Luisetti J (1992b) Efficacity of copper chelate to control bacterial dieback of peaches. Abstr 8th Int Conf Plant Pathogen Bacteria. Versailles, June 1992

Gardan L (1980) Observation de dégâts de Pseudomonas syringae sur forsythia et fusain du Japon. PHM 211, 11-13

Gardan L, Luisetti J, Prunier JP (1971) Premiers résultats sur la sensibilité variétale du Pêcher au dépérissement bactérien ( $P$ seudomonas morsprunorum f sp persicae). CR Séances Acad Agr Fr 6/10/71, 1090-1094

Gardan L, Luisetti J, Prunier JP (1972) Variation in inoculum level of Pseudomonas morsprunorum persicae). CR Séances Acad Agr Fr 6/10/71, 1090-1094

Gardan L, Luisetti, Prunier JP (1972) Variation in inoculum level of Pseudomonas morsprunorum persicae on the leaf surface of peach trees. Proc 3rd Int Conf Plant Pathogen Bacteria 87-94. Wageningen, April 1971

Gardan L, Prunier JP, Luisetti J, Bézelgues JJ (1973) Responsabilité de divers Pseudomonas dans le dépérissement bactérien de l'Abricotier en France. Rev Zool Agric Pathol Végét 4, 112-120

Gardan L, Digat B, Krause A, Cottin S, Lemaire F (1989) La criblure bactérienne du laurier palme. PHM 294, 29-35

Gardan L, Cottin S, Bollet C, Hunault G, Boutefouchet N (1990) Variabilité phénotypique de Pseudomonas syringae $\mathrm{pv}$ syringae provenant de laurier palme et d'hôtes variés. Agronomie 10, 407-416

Gardan L, Cottin S, Bollet C, Hunault G (1991) Phenotypic heterogeneity of Pseudomonas syringae Van Hall. Res Microbiol 142, 995-1004

Garrett CME (1978) Pathogoenic races of Pseudomonas morsprunorum. Proc 4th Int Plant Path Bact 889-890. Angers, mai 1978

Garrett CME, Panagopoulos CG, Crosse JE (1966) Comparison of plant pathogenic pseudomonads from fruit trees. J App/ Bacteriol 29, 342-356

Garriga X, Castano M, Barbé J (1990) Syringomycin production is stimulated by cysteine in Pseudomonas syringae pv syringae. FEMS Microbiol Lett 72, $177-181$

Genevès L (1955) Recherches sur les effets cytologiques du froid. Rev Cytol Biol Végét 16, 1-2, 1-207

Ginzburg BZ (1961) Evidence for a protein gel structure crosslinked by metal cations in the intercellular cement of plant tissue. J Exp Bot 12, 85-107

Gonzales CF, Vidaver AK (1978) Analysis of plasmids of syringomycin producing strains of Pseudomonas syringae. Proc 4th Int Conf Plant Path Bact 31-38. Angers, 1978

Gonzales CF, de Vay JE, Wakeman RJ (1981) Syringotoxin: a phytotoxin unique to citrus isolates of
Pseudomonas syringae. Physiol Plant Pathol 18, 4150

Gonzales CF, Layher SK, Vidaver AK, Olsen RH (1984) Transfer, mapping and cloning of Pseudomonas syringae pv syringae plasmid pCG131 and assessment of its role in virulence. Phytopathology 74, 1245-1250

Goodnow RA, Harrison MD, Morris JD, Sweeting KB, Laduca RJ (1990) Fate of ice nucleation-active Pseudomonas syringae strains alpine soils and waters and in synthetic snow samples. Appl Environ Microbiol 56, 2223-2227

Goto M (1991) Plasmids associated with the resistance to copper and streptomycin in Pseudomonas syringae pv actinidiae. Proc 4th Int working group Pseudomonas syringae pathovars 293-298 Firenze, June 1991

Goto M, Huang BL, Makino T, Goto T, Inaba T (1988) A taxonomic study on ice nucleation-active bacteria isolated from gemmisphere of Tea (Tea sinensis L), phyllosphere of vegetables, and flowers of Magnolia denudata Desr. Ann Phytopathol Soc Jpn 54, 189-197

Green RL, Warren GJ (1985) Physical and functional repetition in a bacterial ice nucleation gene. Nature $317,645-648$

Griffin FL (1911) A bacterial gummosis of cherries. Science 34, 615-616

Gross DC, Cody YS (1985) Mechanism of plant pathogenesis by Pseudomonas species. Can J Microbiol 31, 403-410

Gross DC, Cody YS, Proebsting EL, Radamaker G, Spotts RA (1983) Distribution, population dynamics and characteristics of ice nucleation active bacteria in deciduous fruit tree orchards. App/ Environ Microbiol 46, 1370-1379

Gross DC, Cody YS, Proebsting EL, Radamaker G, Spotts RA (1984a) Ecotypes and pathogenicity of ice-nucleation-active Pseudomonas syringae isolated from deciduous fruit tree orchard. Phytopathology 74, 241-248

Gross DC, Proebsting EL, Andrews Jr, Andrews PK (1984b) The effects of ice nucleation-active bacteria on temperatures of ice nucleation and freeze injury of Prunus flower buds at various stages of development. J Am Soc Hortic Sci 109, 375-380

Gross DC, Proebsting EL, Maccrindle-Zimmerman H (1988) Development, distribution, and characteristics of intrinsic, nonbacterial ice nuclei in Prunus wood. Plant Physiol 88, 915-922

Gvozdyak RI, Rassul FG (1987) Pseudomonas syringae, causal agent of diseases of apple fruits and flowers in the Ukraine. Mikrobiologicheskii 6, 81-82

Hanyu J, Matuoka N, Kon H, Nakayama K (1986) Relation of the environmental conditions of the frost injury. Part 2. Freezing temperature influenced by the wet or dry conditions on the leaf surface of soybean seedlings. J Agr Met 41, 331-335

Hattingh MJ, Roos IMM, Mansvelt EL (1989) Infection and systematic invasion of deciduous fruit trees by 
Pseudomonas syringae in South Africa. Plant Dis 73, 784-789

Henis $Y$, Bashan $Y$ (1986) Epiphytic survival of bacterial leaf pathogens. In: Microbiology of the Phyllosphere (Fokkema NJ, Van Den Heuvel J, eds) Cambridge Univ Press 252-268

Hevesi M, Rivera N, Garcia A (1978) Pseudomonas fluorescens as pathogen on pepper plants. Proc 4th Int Conf Plant Pathol Bact 711-716. Angers 1978

Hewett EW, Young K, Proebsting EL, Mills HH (1978) Modification of critical freezing temperatures in fruit buds by elevated tissue water content. Hortscience $13,247-249$

Hildebrand DC, Schroth MN (1972) Identification of the fluorescent pseudomonads. Proc 3rd Int Conf Plant Path Bact 281-287. Wageningen, April 1971

Hiramatsu M, Wada T, Kanda M, Yamamura H (1990) Effect of kasugamycin on the control of bacterial diseases. Proc 7th Int Conf Plant Patho Bact 219224. Budapest, June 1989. Plant Pathogenic Bacteria (Z Klement, ed)

Hirano SS, Upper CD (1983) Ecology and epidemiology of foliar bacterial plant pathogens. Annu Rev Phytopathol 21, 243-269

Hirano SS, Upper CD (1985) Ecology and physiology of Pseudomonas syringae. Biotechnology 3, 10731078

Hirano SS, Upper CD (1989) Diel variation in population size and ice nucleation activity of Pseudomonas syringae on snap bean leaflets. Appl Environ Microbiol 55, 623-630

Hirano SS, Upper CD (1990) Population biology and epidemiology of Pseudomonas syringae. Annu Rev Phytopathol 28, 155-177

Hirano SS, Mather EA, Kelman A, Upper CD (1978) Ice nucleation activity of fluorescent plant pathogenic pseudomonads. Proc 4th Int Conf Plant Path Bact 717-725. Angers, 1978

Hirano SS, Nordheim EV, Arny DC, Upper CD (1982) Lognormal distribution of epiphytic bacterial populations on leaf surfaces. Appl Environ Microbiol 44, 695-700

Hirano SS, Baker LS, Upper CD (1985) Ice nucleation temperature of individual leaves in relation to population sizes of ice nucleation bacteria and frost injury. Plant Physiol 77, 259-265

Hirano SS, Carroll KL, Stock JD, Upper CD (1988) Rates of intraspecific shifts in Pseudomonas syringae populations under field conditions. Phytopathology 305, 78, 1551 Abstr

Hoitink HAJ, Hagedorn DJ, Mc Coy E (1968) Survival, transmission, and taxonomy of Pseudomonas syringae Van Hall, the causal organism of bacterial brown spot of bean (Phaseolus vulgaris L). Can $J$ Microbiol 14, 437-441

Isogai A, Fukuchi N, Yamashita S, Suyama K, Suzuki A (1989) Syringostatins, novel phytotoxins produced by Pseudomonas syringae pv syringae. Agric Biol Chem 53, 3117-3119
Itier B, Flura D, Brun O, Luisetti J, Gaignard JL, Choisy C, Lemoine G (1991) Analyse de la gélivité des bourgeons de vigne. Expérimentation in situ sur le vignoble champenois. agronomie 11, 169174

Johnson J, Murwin HF (1925) Experiments on the control of wildfire tobacoo. Wis Agr Exp Stn Res Bull 62, 1-35

Kagiwata T, Natsuaki KT, Fuji H, Mukoo H (1990a) Symptoms on various woody plants with inoculation of Pseudomonas syringae pv syringae isolated from lilac. Ann Phytopathol Soc Jpn 56, 83-87

Kagiwata T, Natsuaki KT, Fuji H, Mukoo H (1990b) Overwintering of Pseudomonas syringae pv syringae in lilac twig. J Agri Sc Tokyo Nogyo Daigaku $35,58-64$

Karaca I, Demir G (1988) Investigations on seedborne bacterial pathogens in some plants. Doga, Türk Tarim Ve Ormancik Dergisi 12, 120-131

Kim HK, Orser C, Lindow SE, Sands DC (1987) Xanthomonas campestris pv translucens strains active in ice nucleation. Plant Dis 71, 994-997

Kim KC, Kim IC, Cho BH (1989) Antagonistic activity of an isolate of Candida species to ice nucleationactive Pseudomonas syringae. Phytopathology 79 , 275-277

King EO, Ward MK, Raney DE (1954) Two simple media for the demonstration of pyocyanin and fluorescin. J Lab Clin Medic 44, 301-307

Kinkel LL, Andrews JH, Berbee FM, Nordheim EV (1987) Leaves as islands for microbes. Oecologia $71,405-408$

Klement Z (1963) Rapid detection of the pathogenicity of phytopathogenic pseudomonads. Nature 199, 299-300

Klement Z, Rozsnyay S (1991) The role of the iceminus nucleation active bacteria in the development of canker and dieback diseases of apricots. Proc 4th int working group Pseudomonas syringae pathovars 53-60. Firenze, June 1991

Klement Z, Farkas GL, Lovrekovich L (1964) Hypersensitive reaction induced by phytopathogenic bacteria in the tobacco leaf. Phytopathology 54, 474477

Klement Z, Rozsnyay S, Visnyovsky E (1972) Apoplexy of apricots. I. Bacterial die-back and the development of the disease. Acta Phytopathol 7, 1-3, 1-12

Klement Z, Rozsnyay S, Arsenijevic M (1974) II. Relationship of winter frost and the bacterial canker and dieback of apricots. Acta Phytopathol Acad Sci Hung 9, 35-45

Klingner AE, Palleroni NJ, Pontis RE (1976) Isolation of Pseudomonas syringae from lesions on Vitis vinifera. Phytopathol Z 86, 107-116

Kluyver AJ, Van Niel CB (1936) Propects for a natural System of Classification of Bacteria. Zentrabl Bakteriol Parasitenkd Infektionskr Hyg Abt 2, 19-23, 369-403 
Kozloff LM, Lute M, Westaway D (1984) Phosphatidylinositol as a component of the ice nucleating site of Pseudomonas syringae and Enwinia herbicola. Science 4676, 845-846

de Lange A, Leben C (1970) Colonization of Cucumber buds by Pseudomonas lachrymans in relation of leaf symptoms. Phytopathology 60, 12, 1865-1866

Latorre BA, Jones AL (1979a) Pseudomonas morsprunorum, the cause of bacterial canker of sour cherry in Michigan, and its epiphytic association with $P$ syringae. Phytopathology 69, 335-339

Latorre BA, Jones AL (1979b) Evaluation of weeds and plant refuse as potential sources of inoculum of $P$ seudomonas syringae in bacterial canker of Cherry. Phytopathology 69, 1122-1125

Latorre BA, Gonzales JA, Cox JE, Vial F (1985) Isolation of Pseudomonas syringae $\mathrm{pv}$ syringae from cankers and effect of free moisture on its epiphytic populations on sweet cherry trees. Plant Dis 69, 409-412

Leben C (1965) Epiphytic microorganism in relation to plant diseases. Annu Rev Phytopatho/ 3, 209-230

Leben C (1972) Microorganisms associated with plant buds. J Gen Microbiol 71, 327-331

Leben C (1981) How plant-pathogenic bacteria survive. Plant Dis 65, 633-637

Leben C (1985) Introductory remarks: Biological control strategies in the phylloplane. In: Biological control of the phylloplane (CE Windels, SE Lindow, eds) Am Phytopathol Soc, St Paul 1-5

Leben C, Daft GC, Schmitthenner AF (1968) Bacterial blight of soybeans: population levels of Pseudomonas glycinea in relation to symptom development. Phytopathology 58, 1143-1146

Leben C, Schroth MN, Hildebrand DC (1970) Colonization and movement of Pseudomonas syringae on healthy Bean seedlings. Phytopathology 60, 677680

Legard DE, Hunter JE (1990) Pathogenicity on bean of Pseudomonas syringae pv syringae recovered from phylloplane of weeds and from bean crop residue. Phytopathology 80, 938-942

Lelliott RA, Billing E, Hayward AC (1966) A determinative scheme for the fluorescent plant pathogenic Pseudomonads. J App/ Bacteriol 29, 470-489

Levin Z, Yankofsky SA, Pardes D, Magal N (1987) Possible application of bacterial condensation freezing to artificial rainfall enhancement. $J$ Appl Meteor 26, 1188-1197

Liao CH, Wells JM (1987) Diversity of pectolytic, fluorescent pseudomonads causing soft roots of fresh vegetables at produce markets. Phytopathology 77, 673-677

Liegel W (1965) Physiologie de la résistance au gel de plantes supérieures en particulier dans le cas des arbres fruitiers. Phytoma 172, 20-25

Lindemann J, Constantinidiou HA, Barchet WR, Upper CD (1982) Plants as source of airborne bacteria in- cluding ice nucleation-active bacteria. App/ Environ Microbiol 44, 1059-1063

Lindemann J, Arny DC, Upper CD (1984) Use of an apparent infection threshold population of Pseudomonas syringae to predict incidence and severity of brown spot of bean. Phytopathology 74, 13341339

Lindgren PB, Peet RC, Panopoulos NJ (1986) Gene cluster of Pseudomonas syringae pv phaseolicola controls pathogenicity on bean and hypersensitivity on non-host plants. J Bacteriol 168, 512-522

Lindow SE (1979) Frost damages to potato reduced by bacteria antagonistic to ice nucleation active bacteria. Phytopathology 69, 9, 1036 Abstr

Lindow SE (1982) Population dynamics of epiphytic ice nucleation active bacteria on frost sensitive plants and frost control by means of antagonistic bacteria. In: Plant cold hardiness and freezing stress (Li PH, Sakai A, eds) Acad Press, New York 349-416

Lindow SE (1983a) The role of bacterial ice nuclei in frost injury to plants. Annu Rev Phytopathol 21, 363-384

Lindow SE (1983b) Methods of preventing frost injury caused by epiphytic ice-nucleation-active bacteria. Plant Dis 67, 327-333

Lindow SE (1988a) Lack of correlation of in vitro antibiosis with antagonism of ice nucleation active bacteria on leaf surfaces by non-ice nucleation active bacteria. Phytopathology 78, 444-450

Lindow SE (1988b) Construction of isogenic icestrains of Pseudomonas syringae for evaluation of competition of leaf surfaces. In: Microbiological Ecology (Megusar F, Gantar M, eds) Slovene Soc Microb, Lublijana 509-515

Lindow SE, Connel JH (1984) Reduction of frost injury to almond by control of ice nucleation active bacteria. J Am Soc Hortic Sci 109, 48-53

Lindow SE, Panopoulos NJ (1991) Biological control of frost injury to potato using recombinant icemutants of Pseudomonas syringae. Proc 4th Int working group Pseudomonas syringae pathovars 428-432. Firenze, June 1991

Lindow SE, Rogers S (1991) Copper tolerance of Pseudomonas syringae strains from fruit trees in California. Proc 4th Int working group Pseudomonas syringae pathovars 306-309 Firenze, June 1991

Lindow SE, Arny DC, Upper CD (1978a) Distribution of ice nucleation-active bacteria on plants in nature. Appl Environ Microbiol 36, 831

Lindow SE, Arny DC, Barchet WR, Upper CD (1978b) The role of bacterial ice nuclei in frost injury to sensitive plants, p 249-261. In: Plant cold hardiness and freezing stress, 249-261. Li PH, Sakai A (ed). Acad Press, Inc, New York

Lindow SE, Arny DC, Upper DC (1982a) Bacterial ice nucleation: a factor in frost injury to plants. Plant Physiol 70, 1084-1089 
Lindow SE, Hirano DC, Arny DC, Upper CD (1982b) Relationship between ice nucleation frequency of bacteria and frost injury. Plant Physiol 70, 10901093

Lindow SE, Lahue E, Govindarajan AG, Panopoulos NJ, Gies D (1989) Localization of ice nucleation activity and the iceC gene product in Pseudomonas syringae and Escherichia coli. Mol Plant Microbe Inter 2, 5, 262-272

Lovrekovich L, Klement Z, Dowson WJ (1963) Serological investigation of Pseudomonas syringae and Pseudomonas morsprunorum strains. Phytopathol Z 47, 19-24

Luisetti J (1978) L'influence du gel sur le développement des phytobactérioses. Lutte contre les gelées. In : Journées nationales dinformation INVUFLEC 89-98. Angers, février 1978

Luisetti J (1983) Quelques aspects de la variabilité de Pseudomonas persicae, agent du dépérissement bactérien du Pêcher. $C R 3^{e}$ colloque Rech Fruit 187-200. Bordeaux, 1983

Luisetti J, Paulin JP (1972) Études sur les bactérioses des arbres fruitiers. 3. Recherche de Pseudomonas syringae à la surface des organes aériens du Poirier et étude de ses variations quantitatives. Ann Phytopathol 4, 215-227

Luisetti J, Drouhard A (1981) Dépérissement bactérien du pêcher : quelques caractéristiques de la dissémination de l'agent responsable. $C R 1^{\text {er }}$ colloque Rech Fruit 227-228. Bordeaux 1981

Luisetti J, Gaignard JL (1984a) Variations in the distribution of Pseudomonas persicae epiphytic populations. Proc 2nd Working Group Pseudomonas syringae pathovars 17-18. Sounion, April 1984

Luisetti J, Gaignard JL (1984b) Variabilité de Pseudomonas persicae, agent du dépérissement bactérien du Pêcher. In : Les colloques de I'INRA. Variation et variabilité des agents phytopathogènes 207-212 (INRA, ed) $26^{\circ}$ colloque SFP, Avignon, mai 1984

Luisetti J, Gaignard JL (1985) Gel de printemps et bactéries glaçogènes. Arboric Fruit 373, 46-48

Luisetti J, Gaignard JL (1986) Les bactéries glaçogènes et le gel de printemps. Viti 97, 13-14

Luisetti J, Gaignard JL (1987a) Bacterial populations in buds and probability of frost injury on grapevine. Proc 6th Int Conf Plant Pathogen Bacteria 983-993 Maryland June 1985 (Martinus Nijhoff Publishers, eds) Dordrecht

Luisetti J, Gaignard JL (1987b) Deux maladies bactériennes du kiwi en France. Phytoma 391, 42-45

Luisetti J, Gaignard JL (1989a) Implication du pouvoir glaçogène des bactéries dans le développement de phytobactérioses. $C R 1^{\text {er }}$ Congrès SFP (ENSAR, Rennes, éd) Rennes, nov 1986

Luisetti J, Gaignard JL (1989b) Les bactéries glaçogènes et leur rôle dans les gelées de printemps. $C$ $R$ Séances Acad Agric Fr 75, 93-98

Luisetti J, Gaignard JL (1991) Le dessèchement bactérien du Poirier dû à Pseudomonas syringae pv sy- ringae. In : Protection intégrée du verger, Pommier, Poirier 115-117 (CTIFL-INRA, éds) C R Entretiens techniques d'Angers, Nv 1990

Luisetti J, Prunier JP, Gardan L (1972) Un milieu pour la mise en évidence de la production d'un pigment fluorescent par Pseudomonas morsprunorum $\mathrm{f} \mathrm{sp}$ persicae. Ann Phytopathol 4, 295-296

Luisetti J, Gardan L, Prunier JP (1973a) Heterogeneity of $P S$ syringae from apricot trees. ISPP Phytobacteriology section. Proc working group Pseudomonas syringae 97-98, Angers, Avril 1973

Luisetti J, Gardan L, Prunier JP (1973b) Études sur les bactérioses des arbres fruitiers. VI. Étude du pouvoir pathogène de $P$ morsprunorum f sp persicae. Influence de la dose d'inoculum. Ann Phytopathol 5, 4, 347-353

Luisetti J, Gaignard JL, Pacqueteau B, Lafuste JP (1984) Le dépérissement bactérien du Pêcher. Phytoma 358, 29-32

Luisetti J, Gaignard JL, Ridé M (1990) Ability of kasumin to control some phytopathogenic bacteria. Proc 7th Int Conf Plant Patho Bact 213-218. Budapest, June 1989. Plant Pathogenic Bacteria (Z Klement, ed)

Luisetti J, Gaignard JL, Devaux M (1991) Pseudomonas syringae pv syringae as one of the factors affecting the ice nucleation of grapevine buds in controlled conditions. J Phytopathol 133, 334-344

Luisetti J, Gaignard JL, Vigouroux A, Saunier R, Lafuste JP, Charras J (1992) Pêcher, le dépérissement bactérien. Arboric Fruit 447, 19-28

Mc Carter SM, Jones JB, Gitaitis RD, Smitley DR (1983) Survival of Pseudomonas syringae pv tomato in association with tomato seed, host tissue, and epiphytic weeds hosts in Georgia. Plant Dis 13931398

Mc Guire RG, Kelman A (1986) Calcium in potato tuber cell walls in relation to tissue maceration by Enwinia carotovora pv atroseptica. Phytopathology $74,1250-1256$

Mc Innes TB, Gitaitis RD, Mc Carter SM, Jaworski CA, Phatak SC (1988) Airborne dispersal of bacterial in tomato and pepper transplant fields. Plant Dis 72, 575-579

Mc Keen WE (1955) Pear blast in Vancouver Island. Phytopathology 45, 629-632

Maki LR, Willoughty KJ (1978) Bacteria as biogenic sources of freezing nuclei. J App/ Meteorol 17, 1049-1053

Maki LR, Gaylan EL, Chang-Chien MM, Cadwell DR (1974) lce nucleation induced by Pseudomonas syringae. Appl Microbiol 28, 456-459

Malvick DK, Moore LW (1988) Population dynamics and diversity of Pseudomonas syringae on maple and pear trees and associated grasses. Phytopathology 78, 1366-1370

Manceau C (1984) Utilisation des antibiotiques en agriculture : étude des risques potentiels de sélection et de dissémination des gènes d'antibiorésis- 
tance et caractérisation du support génétique de ces caractères. Thèse $3^{e}$ cycle. Univ ClermontFerrand

Manceau C, Chevron M (1989) Étude expérimentale du comportement épiphyte de quelques phytobactéries sur plantes homologues et hétérologues. $C A$ $1^{\text {er }}$ Congrès SFP, Rennes, nov 1987, 114-115. ENSAR Rennes (éd)

Manceau C, Lalande JC, Lachaud G, Chartier R, Paulin JP (1990) Bacterial colonization of flowers and leaf surface of pear trees. Acta Hortic 273, 73-81

Mansvelt EL, Hattingh MJ (1985) Pear blossom blast in South africa caused by Pseudomonas syringae pv syringae. Plant Pathol 35, 337-343

Mansvelt EL, Hattingh MJ (1987a) Scanning electron microsopy of colonization of pear leaves by Pseudomonas syringae pv syringae. Can $J$ Bot 65, 2517-6522

Mansvelt EL, Hattingh MJ (1987b) Scanning electron microscopy of pear blossom invasion by Pseudomonas syringae pv syringae. Can J Bot 65, 2523-2529

Mansvelt EL, Hattingh MJ (1988) Resident populations of Pseudomonas syringae pv syringae on leaves, blossoms, and fruits of apple and pear trees. J Phytopathol 121, 135-142

Mansvelt EL, Hattingh MJ (1989) Scanning electron microscopy of invasion of apple leaves and blossoms by Pseudomonas syringae pv syringae. Appl Environ Microbiol 55, 533-538

Matthee FN, Erskine JV (1971) Bacterial canker of stone fruits. The Deciduous Fruit Grower 21, 204206

Mew TW, Kennedy BW (1971) Growth of Pseudomonas glycinea on the surface of Soybean leaves. Phytopathology 61, 715-716

Menkissoglu O, Lindow SE (1991a) Relationship of free ionic copper and toxicity to bacteria in solutions of organic compounds. Phytopathology 81, 1258-1263

Menkissoglu O, Lindow SE (1991b) Chemicals forms of copper on leaves in relation to the bactericidal activity of cupric hydroxide deposits on plants. Phytopathology 81, 1263-1270

Migula W (1984) Über ein neues System der Bakterien. Arb Bakteriol Inst Karlsruhe 1, 235-238 (All)

Mills D, Mukhopadyay P (1990) Organisation of hrpM locus of Pseudomonas syringae pv syringae and its potential function in pathogenesis. In: Pseudomonas: biotransformations, pathogenesis, an evolving biotechnology (Silver S, Chakrabarty AM, Iglewski B, Kaplan S, eds) Am Soc Microbiol, Washington, DC 45-47

Mitchell RE (1977) Isolation and structure of a chlorosis inducing toxin of Pseudomonas phaseolicola. Phytochemistry 15, 1941-1947

Mitchell RE (1982) Coronatine production by some phytopathogenic Pseudomonas. Physiol Plant Patho/ 20, 83-89
Montesinos E, Vilardell LP (1991) Relationship among population levels of Pseudomonas syringae, amount of ice nuclei, and incidence of blast of dormant flower buds in commercial pear orchards in Catalunya, Spain. Phytopathology 81, 113-119

Moo YY, Gross DC (1991) Plant signal molecules activate the syrA gene, which is required for syringomycin production by Pseudomnas syringae pv syringae. J Bacteriol 173, 5784-5792

Moore WEC, Moore LVH (1989) Index of the bacterial and yeast nomenclatural changes $72 \mathrm{p} \mathrm{IJSB}, \mathrm{ASM}$, Washington

Morris CE, Rouse DI (1985) Role of nutrients in regulating bacterial populations. In: Biological control on the phylloplane (CE Windels, SE Lindow, eds) Am Phytopathol Soc, St Paul 63-82

Nemeth J, Aponyi I, Horn A, Ogawa Y (1990) Use of antibiotics, kasugamycin to control bacterioses of vegetables in Hungary. Proc 7 th Int Conf Plant Pathogen Bacteria, 247-251. Budapest, June 1989. Plant Pathogen Bacteria (Z Klement, ed)

Opgenorth DC, Lai M (1983) Pseudomonas canker of kiwifruit. Plant Dis 67, 1183-1184

Orser CS, Statskawicz BJ, Loper J, Panopoulos NJ, Dahlbeck D, Lindow SE, Schroth MN (1983) Cloning of gene involved in bacterial ice nucleation and fluorescent pigment/siderophore. In: Molecular Genetic of the Bacteria. Plant Interaction (Pahler A, ed) $353-360$

Orser CS, Staskawicz BJ, Panopoulos NJ, Dahlbeck $D$, Lindow SE (1985) Cloning and expression of bacterial ice nucleation genes in Escherichia coli. $J$ Bacteriol 164, 359-366

Otta JD, English H (1970) Epidemiology of the bacterial canker disease of French prune. Plant Dis Reptr 54, 332-336

Otta JD, English H (1971) Serology and pathology of Pseudomonas syringae. Phytopathology 61, 443452

Palleroni NJ (1984) Genre 1 Pseudomonas Migula. In: Bergey's Manual of Systematic Bacteriology (Krieg NR, Holt JG, eds) 1, 141-199

Palleroni NJ, Ballard RW, Ralston E, Doudoroff $M$ (1972) Deoxyribonucleic acid homologies among some Pseudomonas species. J Bacteriol 110, 1-11

Palleroni NJ, Kunisawa R, Contopoulo R, Doudoroff $M$ (1973) Nucleic acid homologies in the genus Pseudomonas. Int J Syst Bacteriol 23, 333-339

Panagopoulos CG (1966) Studies on the source of inoculum for blast and black pit of Citrus. Proc 1rst Congr Mediterr Phytopathol. Union 340-345

Panagopoulos CG (1969) The disease "Tsilik marasi" of grapevine: its description and identification of the causal agent (Xanthomonas ampelina sp nov). Ann Inst Phytopathol Benaki 9, 59-81

Panagopoulos CG, Crosse JE (1964) Frost injury as a predisposing factor in blossom blight of pear caused by Pseudomonas syringae Van Hall. Nature 202,1352 
Parker KG, Burkholder WH (1950) Pseudomonas syringae Van Hall on apple and pear in New York State. Plant Dis Rep 34, 101-110

Parungo FP, Lodge JPJr (1965) Molecular structure and ice nucleation of some organics. J Atmos Sci 22, 309-313

Parungo FP, Lodge JPJr (1967) Amino acids as ice nucleators. J Atmos Sci 24, 274-277

Patushenko LT, Simonovich ID (1979) Groupes sérologiques des bactéries phytopathogènes du genre Pseudomonas. II. Parentés antigéniques de diverses espèces. Mikrobiol Zh 41, 330-339

Paulin JP, Luisetti J (1978) Ice nucleation activity among phytopathogenic bacteria. Proc 4th Int Conf Plant Path Bact 725-731. Angers 1978

Pecknold PC, Grogan RG (1973) Deoxyribonucleic acid homology group among phytopathogenic Pseudomonas species. Int J Syst Bacteriol 23, 111-121

Pesrlasca G (1960) Relationships among isolates of Pseudomonas syringae pathogenic on stone fruit trees. Phytopathology 50, 889-899

Phelps P, Giddings TH, Prochoda M, Fall R (1986) Release of cell-free ice nuclei by Erwinia herbicola. $J$ Bacteriol 167, 496-502

Pooley L, Brown TA (1991) Effects of culture conditions on expression of the ice nucleation phenotype of Pseudomonas syringae. FEMS Microbiol Lett 77, 229-232

Power BA, Power RF (1962) Some amino-acids as ice nucleators. Nature 194, 1170-1171

Prévot AR (1961) Traité de systématique bactérienne 2 (Dunod, Paris, éd) 42-83

Proebsting EL, Andrews Jr, Andrews PK, Gross D (1982) Supercooling young developing fruit and floral buds in deciduous orchards. Hortscience 17, $67-$ 68

Prunier JP (1986) Susceptibility of sweet cherry (Prunus avium) to Pseudomonas syringae pv morsprunorum in mediterranean area. Proc 6th Congr Union Phytopathol Mediterr 292-294. Cairo, Oct 1986

Prunier JP, Luisetti J (1983) Phytopathogenic pseudomonads behaviour in natural conditions in connection with fruit trees infections. Proc 4th Int Congr Plant Pathol 35. Melbourne, 1983

Prunier JP, Cotta J (1985) Le chancre bactérien du Cerisier en France (1re partie). Description de la maladie. Arboric Fruit 374, 39-42

Prunier JP, Cotta J (1987) Le dépérissement bactérien ( $P$ seudomonas spp) de l'abricotier : situation en France. Bulletin OEPP 17, 251-256. Conf OEPP Angers, mai 1986

Prunier JP, Bordjiba (1991) Effect of frost on bacterial necrosis of apricot buds. Acta Hortic 293, 495-503

Prunier JP, Luisetti J, Gardan L (1970a) Études sur les bactérioses des arbres fruitiers. II. Caractérisation d'un Pseudomonas non-fluorescent, agent d'une bactériose nouvelle du Pêcher. Ann Phytopathol 2, 181-197
Prunier JP, Ridé M, Lafon R, Bulit J (1970b) La nécrose bactérienne de la vigne. $C R$ Acad Agric $\mathrm{Fr}$ Séance 1/7/1970, 975/982

Prunier JP, Luisetti J, Gardan L (1973) Études sur les bactérioses des arbres fruitiers. $V$. Étude du pouvoir pathogène de Pseudomonas morsprunorum $\mathrm{f}$ sp persicae, agent du dépérissement bactérien du pêcher. Méthodologie : premiers résultats sur l'influence de la date d'inoculation. Ann Phytopathol 5 , 327-346

Prunier JP, Luisetti J, Gardan L (1974) Étude sur les bactérioses des arbres fruitiers, essais de lutte chimique contre le Dépérissement Bactérien du Pêcher en France. Phytiatr-Phytopharm 23, 71-88

Prunier JP, Bonnat R, Cotta J, Pelissier A (1985) Le chancre bactérien du Cerisier en France ( $3^{e}$ partie). La lutte chimique contre Pseudomonas morsprunorum. Arboric Fruit 376, 47-50

Ridé M (1967) Quelques problèmes d'actualité concernant l'étude des maladies bactériennes des végétaux. Phytiatr-Phytogram 16, 127-139

Ridé M, Sutic D (1957) Un dessèchement des pousses de poirier d'origine bactérienne. $C R A c a d$ Agric Fr 44, 384-387

Ritzéma BJ (1989) Eine Bakterienziekte der Syringen. Tijdschr Plantenziekten 5, 177-183

Roos IMM, Hattingh MJ (1983) Scanning electron microscopy of Pseudomonas syringae pv morsprunorum on sweet cherry leaves. Phytopathol Z 108, 18-25

Roos IMM, Hatting MJ (1986a) Weeds in orchards as potential source of inoculum for bacterial canker of stone fruit. Phytophylactica 18, 5-6

Roos IMM, Hattingh MJ (1986b) Pathogenic Pseudomonas ssp in stone fruit buds. Phytophylactica 18, 7-9

Roos IMM, Hattingh MJ (1986c) Resident populations of Pseudomonas syringae on stone fruit tree leaves in South Africa. Phytophylactica 18, 55-58

Roos IMM, Hattingh MJ (1987) Pathogenicity and numerical analysis of phenotypic features of Pseudomonas syringae strains isolated from deciduous fruit trees. Phytopathology 77, 900-908

Rose $\mathrm{DH}$ (1917) Blister spot of apples and its relation to a disease of apple bark. Phytopathology 7, 198-208

Rosinski J, Parungo F (1966) Terpene-iodine compounds as ice nuclei. J Appl Meteorol 5, 119-123

Rouse DI, Nordheim EV, Hirano SS, Upper CD (1985) A model relating the probability of foliar disease incidence to the population frequencies of bacterial plant pathogens. Phytopathology 75, 505-509

Sakai R, Nishiyama K, Ichihara A, Shiraishi K, Sakamura $S$ (1979) The relation between bacterial toxic action and plant growth regulation. In: Recognition and specificity in plant-host parasite interaction (JM Daly, Uritani, Jpn Sci So Press, Tokyo Univ Park Press, Baltimore, eds) 165-179

Samson R, Saunier M (1987) Désignation de références sérologiques pour six sérogroupes de pa- 
thovars de Pseudomonas syringae sur la base de leur lipopolyoside. Bull OEPP 17, 165-171. Conf OEPP Angers, mai 1986

Samson R, Maufras JY, Poutier F, Rat B, Gaignard JL (1988) Nouvelles données épidémiologiques sur la graisse du pois protéagineux. $2^{e}$ Conf Int sur les maladies des plantes 943-949. ANPP, nov 1988

Sands DC, Schroth MN, Hildebranb DC (1970) Taxonomy of phytopathogenic Pseudomonads. J Bacteriol 101, 9-23

Sasser M, Miller L (1984) Identification of pseudomonads by fatty acid profiling. Proc 2 nd working group on Pseudomonas syringae pathovars 45-46 Sounion, April 1984

Schnell RC, Vali G (1976) Biogenic ice nuclei. Part I: Terrestrial and marine sources. J Atmos Sci 33, 1554-1564

Seemüller E, Arnold M (1978) Pathogenicity, syringomycin production and other characteristics of Pseudomonad strains isolated from deciduous fruit trees. Proc 4th Int Conf Plant Path Bact 703-710. Angers, 1978

Sequeira $L$ (1978) Lectins and their role in hostpathogen specificity. Annu Rev Phytopathol 16, 453-481

Sequeira $L$ (1983) Mechanisms of induced resistance in plants. Annu Rev Microbiol 37, 125-135

Sequeira $L$ (1985) Surface components involved in bacterial pathogen-plant host recognition. J Cell Sci Supp/2, 301-316

Shane SL, Baumer JS (1987) Population dynamics of Pseudomonas syringae pv syringae on spring wheat. Phytopathology 77, 1399-1405

Sikyta B, Hegerova H, Dubrovsky M, Petera V (1989) Cultivation and properties of ice-nucleation active bacteria Pseudomonas syringae CCM 4073. Biotechnol Lett 11, 5, 307-312

Simon EW (1978) The symptoms of calcium deficiency in plants. New Phytol $80,1-15$

Sinden SL, Durbin RD (1970) A comparison of the chlorosis-inducing toxin from Pseudomonas coronofaciens with wildfire toxin from Pseudomonas tabaci. Phytopathology 60, 360-364

Sobiczewski P (1978) Epiphytic populations of pathogenic pseudomonads on sour cherry leaves. Proc 4th Int Conf Plant Path Bact 753-762. Angers, 1978

Sobiczewski $P$ (1987) Antagonistic bacteria in relation to Pseudomonas syringae pv syringae occuring in necrosis and cankers of sour cherry trees. Fruit $\mathrm{Sci}$ Rept 14, 4, 179-185

Sobiczewski P, Chiou CS, Jones AL (1991) Streptomycin-resistant epiphytic bacteria with homologous DNA for streptomycin resistance in Michigan apple orchards. Plant Dis 75, 1110-1113

Some A, Samson R (1991) Critères protéiques et enzymatiques pour la caractérisation des Pseudomonas fluorescents phytopathogènes. $C R$ Séances Acad Sci Paris 312, 3, 203-208
Sorauer $P$ (1981) Neue krankheitserscheinung bei syringae. Ztschr Pflanzenkrank 1, 186-188

Soulage $\mathrm{G}$ (1957) Les noyaux de congélation de l'atmosphère. Ann Géophys 13, 103-134

Staskawicz B, Dahlbeck D, Keen N, Napoli C (1987) Molecular characterization of cloned avirulence genes from race 0 and race 1 of Pseudomonas syringae pv glycinea. J Bacteriol 169, 5789-5794

Stead DE (1987) Identification of Pseudomonas syringae pathovars by fatty acid profiling. Proc 3rd int working group Pseudomonas syringae pathovars 14-16. Lisboa, Sept 1987

Stead DE, Holland DT (1987) Identification of Pseudomonas syringae pathovars from peas by computer assisted polyacrylamide gel of electrophoresis of whole cell proteins. Proc 3rd int working group Pseudomonas syringae pathovars 27-29. Lisboa, Sept 1987

Stewart WW (1971) Isolation and proof structure of wildfire toxin. Nature 229, 174-178

Stout JD (1960) Biological studies of some tussockgrassland soils. Bacterial of two cultivated soils. NZ $J$ Agric Res 3, 214-223

Süle $S$, Seemüller $E$ (1987) The role of ice formation in the infection of sour cherry leaves by Pseudomonas syringae pv syringae. Phytopathology 77, 2, 173-177

Sundin GW, Jones AL, Olson BD (1988) Overwintering and population dynamics of Pseudomonas syringae pv syringae and $P s \mathrm{pv}$ morsprunorum on sweet and sour cherry trees. Can J Plant Pathol 10, 281-288

Sundin GW, Jones AL, Fulbright DW (1989) Copper resistance in Pseudomonas syringae pv syringae from cherry orchards and its associated transfer in vitro and in planta with plasmid. Phytopathology 79 , 861-865

Surico G, Sparapano L, Lerario P, Durbin RD, lacobellis $N$ (1975) Cytokinin-like activity in extracts from the culture filtrate of Pseudomonas savastanoi. Experentia $31,929-930$

Takanashi K (1988) Bacterial canker of Japanese plum caused by Pseudomonas syringae pv morsprunorum. Bull Fruit Tree Res Stn, A (Yatabe) 15, 117-12

Vali G, Christensen M, Fresh RW, Gaylan E, Maki LR, Schnell RC (1976) Biogenic ice nuclei. Part II: Bacterial sources. J Atmos Sci 33, 1565-1570

Van Hall CJJ (1902) Bijdragen tot de kennis der Bakterieele Plantenziekten. Thesis, Amsterdam, 191198

de Vay JE, Lukezic FL, Sinden SL, English H, Coplin DL (1968) A biocide produced by pathogenic isolates of Pseudomonas syringae and its possible role in the bacterial canker disease of peach trees. Phytopathology 58, 95-101

Vigouroux A (1968) Premières observations sur une nouvelle bactériose chez le Pêcher. $C R$ Séances Acad Agric Fr 54, 1021-1026 
Vigouroux A (1970) Études sur les bactérioses des arbres fruitiers. 1. Une nouvelle bactériose du Pêcher : description, étiologie, développement du parasite. Ann Phytopathol 2, 155-179

Vigouroux A (1974) Obtention de symptômes de bactériose du Pêcher (Pseudomonas morsprunorum $\mathrm{f}$ $\mathrm{sp}$ persicae) sur rameaux de Pêcher détachés et conservés en survie. Effet du froid. Ann Phytopathol $6,95-98$

Vigouroux A (1979) Incidence des basses températures sur la sensibilité du pêcher au dépérissement bactérien. Ann Phytopathol 11, 231-239

Vigouroux A (1989) Ingress and spread of Pseudomonas in stems of peach and apricot promoted by frost-related water-soaking of tissues. Plant Dis 73, 854-855

Vigouroux A (1991) Mechanism of cold-induced peach infection by Pseudomonas $\mathrm{s}$ pv persicae water congestion in tissues. J Phytopathol 132, 139-145

Vigouroux A, Huguet C (1980) Prédisposition du Pêcher au dépérissement bactérien sur sols d'arènes et de diluvion. Ann Phytopathol 12, 312

Vigouroux A, Berger JF, Bussi C (1987) La sensibilité du pêcher au dépérissement bactérien en France : incidence de certaines caractéristiques du sol et de l'irrigation. Relations avec la nutrition. agronomie 7, 483-495

Waissbluth ME, Latorre BA (1978) Source and seasonal development of inoculum for pear blast in Chile. Plant Dis Rept 62, 651-655

Walker JC, Patel PN (1964) Splash dispersal and wind as factors in epidemiology of halo blight of bean. Phytopathology 54, 140-141

Warren G, Corotto L (1989) The consensus sequence of ice nucleation proteins from Erwinia herbicola, Pseudomonas fluorescens and Pseudomonas syringae. Gene 85, 239-242

Warren G, Corotto L, Wolber P (1986) Conserved repeats in diverged ice nucleation structural genes from two species of Pseudomonas. Nucleic Acid Res 14, 8047-8060

Watanabe M, Arai S (1987) Freezing of water in the presence of ice nucleation active bacterium, Erwinia ananas, and its application for efficient freezedrying of foods. Agric Biol Chem 51, 557-563

Weaver DJ (1978) Interaction of Pseudomonas syringae and freezing in bacterial canker on excised peach twigs. Phytopathology 68, 1460-1463

Weaver DJ, Gonzales CF, English H (1981) Ice nucleation by Pseudomonas syringae associated with canker production in peach. Phytopathology 71, 109

Welch JF, Speidel HK (1989) Visualization of potential bacterial ice nucleation sites. Cryo-Lett 10, 309-314

Whitesides SK, Spotts RA (1991) Induction of pear blossom blast caused by Pseudomonas syringae pv syringae. Plant Pathol 40, 118-127

Willis DK, Hrabak EM, Rich JJ, Barta TM, Lindow SE, Panopoulos NJ (1990) Isolation and characteriza- tion of a Pseudomonas syringae pv syringae deficient in lesion formation on bean. Mol PlantMicrobe Interact 3, 149-156

Wilson EE (1934) A bacterial canker of pear trees new to California. Phytopathology 24, 534-537

Wimalajeewa DLS, Flett JD (1985) A study of populations of Pseudomonas syringae pv syringae on stonefruits in Victoria. Plant Pathol 34, 248-254

Wimalajeewa DLS, Hayward AC, Greenhalgh FC (1983) A bacterial leaf spot of Protea cynaroïdes (king protea). Ann Appl Biol 102, 339-344

Winslow CEA, Broadhurst J, Buchanan RE, Krumwiede C, Rogers JrLA, Smith GH (1917) The families and genera of the bacteria. Preliminary report of the Committee of the Society of American Society of American Bacteriologists on characterization and classification of bacterial types. J Bacteriol 2, 506-566

Wolber PK, Warren CJ (1986) Structural modelling of the ice nucleation protein of Pseudomonas syringae. Biophys J 49, 293 Abstr

Wormald H (1931) The symptoms of bacterial canker in plum trees. Journ Pom \& Hort Sci 9, 239-256

Xu GW, Gross DC (1988a) Evaluation of the role of syringomycin in plant pathogenesis by using $\operatorname{Tn} 5$ mutants of Pseudomonas syringae pv syringae defective in syringomycin production. Appl Environ Microbiol 54, 1345-1353

Xu GW, Gross DC (1988b) Physical and functional analyses of the syrA and syrB genes involved in syringomycin production by Pseudomonas syringae pv syringae. J Bacteriol 170, 5680-5688

Yamaka S, Ozaki M, Kato S (1980) Some observations on angular leafspot of cucumber with a scanning electron microscope. Tohoku Jpn Agric Res 30, 135-141

Yankofsky SA, Levin Z, Moshe A (1981a) Association with Citrus of ice-nucleating bacteria and their possible role as causative agents of frost damage. Current Microbiol 5, 213-217

Yankofsky SA, Levin Z, Bertold T, Sandlerman N (1981b) Some basic characteristics of bacterial freezing nuclei. J App/Meteor 20, 1013-1019

Yelenosky G (1983) Ice nucleation active (INA) agents in freezing of young citrus trees. $J$ Am SoC Hortic Sci 108, 1030-1034

Yessad S, Manceau C, Luisetti J (1991) Difference between multiplication of $P s$ pv syringae strains, on pear and bean leaves in growth chamber. Proc 4th Int working group Pseudomonas syringae pathovars 126. Firenze, June 1991

Yessad S, Manceau C, Luisetti J (1992) A detached leaf assay to evaluate virulence and pathogenicity of strains of Pseudomonas syringae pv syringae on pear. Plant Dis 76, 370-373

Young JM (1978) Survival of bacteria on Prunus leaves. Proc 4th Int Conf Plant Path Bact 779-786. Angers, 1978 
Young JM (1988) Pseudomonas syringae pv persicae from nectarine, peach, and Japanese plum in New Zealand. Bulletin OEPP 18, 141-151

Young JM (1991) Pathogenicity and identification of the lilac pathogen, Pseudomonas syringae pv syringae Van Hall 1902. Ann Appl Biol 118, 283-298

Young JM, Dye DW, Bradbury JF, Panagopoulos CG, Robbs CF (1978) A proposed nomenclature and classification for plant pathogenic bacteria. $N Z J$ Agric Res 21, 153-177

Young JM, Bradbury JF, Davis RE, Dickey RS, ErcoIani GL, Hayward AC, Vidaver AK (1991) Nomenclatural revisions of plant pathogenic bacteria and list of names 1980-1990. Rev Plant Pathol 70, 4, 211-221

Zhang L, Takemoto JY (1987) Effects of Pseudomonas syringae phytotoxin, syringomycin on plasma membrane functions of Rhodoturula pilimanae. Phytopathology 77, 297-303

Zeller VW, Schmidle A (1979) The effect of frost on the infection by Pseudomonas syringae Van Hall on leaves of sour cherries (Prunus cerasus). Nachrichtenbl deutsch Pflanzenschutzdienstes Braunschweig 31, 97-99

Zettlemoyer AC, Tcheurekdlian N, Chessick JJ (1961) Surface properties of silver iodide. Nature 192, 653 